\title{
Mapping Industrial Symbiosis Development In Europe_typologies of networks, characteristics, performance and contribution to the Circular Economy_
}

\author{
Teresa Domenech ${ }^{1,}{ }^{,}$, Raimund Bleischwitz ${ }^{1}$, Doranova, A. ${ }^{2}$, Panayotopoulos, D. ${ }^{1}$, Roman, L. ${ }^{2}$ \\ 1 University College London, Central House, 14 Upper Woburn Place, London WC1H 0NN, United \\ Kingdom; \\ 2 Technopolis Group, Avenue de Tervuren 188A, B-1150 Brussels, Belgium \\ * Correspondence: E-Mail: t.domenech@ucl.ac.uk
}

\section{Abstract}

Last years have seen a surge of Industrial Symbiosis (IS) development in association with ad-hoc widespread policies to encourage more circular and sustainable practices in the manufacturing sector. Developments in Europe, despite having attracted less attention in the literature, have been significant, driven both by public and private initiative. This paper provides an updated overview of IS activity in Europe, with a mapping of key networks, and a study of prevailing typologies of networks, size, geographical distribution and main streams/ resources traded. The analysis is based on a combination of desk research, gathering of primary data from case studies, a survey to IS network facilitators $(n=22)$ and in-depth interviews and focus groups (3) with IS practitioners, policy officers and industry representatives $(n=25)$. The analysis identified pockets of IS activity across all Europe, although varying in nature, resources exchanged and scale and scope of the initiatives. The average size of the mapped networks is approx. 473 members, but the median is approx. 100 members, which indicates high variability of sizes. The geographical scope of the synergies also seems to be dependent upon the following factors: 1 ) the type of waste stream/by-product; 2) transport costs and 3) market value of secondary materials. Types of waste streams exchanged common to most networks, are chemicals (e.g. chemical base products), biomass and agriculture by-products, wood and wood pellets, plastics, reusable construction materials, equipment, inert waste and water (different qualities including industrial water), residual heat and steam. The paper also discusses key obstacles facing IS development in Europe highlighting: 1) weakness of economic incentives given the low margin of IS projects associated to undeveloped secondary markets; 2) geographical variation of incentives and drivers, given differences in policy frameworks and support mechanisms (e.g. landfill tax levels) and 3) legislative issues that make transport over geographic boundaries extremely complex and administratively burdensome. Finally, the paper concludes with a general discussion of the potential of IS to contribute to the transition to the circular economy (CE) in Europe and identifies some key areas of future research. 


\section{INTRODUCTION}

\subsection{Industrial symbiosis and the Circular Economy}

Industrial symbiosis (IS) is a system approach to a more sustainable and integrated industrial system, which identifies business opportunities that leverage underutilised resources (such as materials, energy, water, capacity, expertise, assets etc.) (Lombardi \& Laybourn, 2012). IS involves organisations operating in different sectors of activity that engage in mutually beneficial transactions to reuse waste and by-products, finding innovative ways to source inputs and optimising the value of the residues of their processes. IS has also been seen as a practical approach to "enhance resource efficiency, reduce waste generation and GHG emissions via material, energy, by-products exchange between different processes and industries" (Sun et al., 2017), and thus has been included at the core of strategies to promote the transition towards the Circular Economy (CE), through promoting flows of resources through multiple cycles across different sectors of activities and supply chains.

The concept of the CE has recently attracted increasing policy and business attention. It proposes an alternative to the predominant 'take-make-consume-dispose' linear model of production and consumption, which is 'restorative and regenerative by design' and where resources are maintained at the 'highest utility and value' for longer (EMF, 2013). The concept of the CE is intuitively easy to understand, however, realising it in the practice is a complex issue. Industrial symbiosis has been identified as a practical approach to close the loop of manufacturing processes by transforming waste of different processes and industries in feedstock to other industries and, therefore, enabling the transition from wasteful to closed loop systems (Wen and Meng, 2015), where materials are kept in productive cycles for longer reducing the pressure on primary raw materials and impacts linked to waste generation and GHG emissions. IS is considered a solution to enhance environmental sustainability while achieving economic benefits simultaneously and one of the practical routes to embed CE in manufacturing activities (Lieder and Rashid, 2016). Policy developments in both China and Europe have attempted to accelerate the transition towards the CE (McDowall et al., 2017).

In China, the CE law (2008) has been supported by specific targets and programmes included in the 12th and 13th five-year plants (Matthews and Tan, 2011). Eco-Industrial Parks and Economic Zones have been the target of many of these initiatives to use waste as a resource (see, for example, Wen and Meng, 2015; Yuan and Shi, 2009). From the EU side, building on the Europe 2020 strategy, the European Commission (EC) launched a revised CE package in 2015 'closing the loop_ An action Plan for the Circular Economy (EC, 2015), which includes measures covering the whole cycle of materials: from production and consumption to waste management and concrete measures to stimulate the market for secondary raw materials. The programme specifically refers to the role of IS as an innovative approach to transform 'waste or by-products of one industry to become inputs for another' and proposes that the revision of the waste directives contributes to clarify rules on by-products to create a level-playing field for IS in Europe.

While numerous case studies analyses assess the structure, conditions and performance of IS initiatives in Europe, a comprehensive vision of IS activity in Europe is still missing. This paper undertakes a rigorous assessment of current initiatives in Europe, based on a thorough mapping exercise and provides insights of the nature of IS activity in Europe. Section 2 includes an overview of the state of IS literature in Europe. Section 3 presents the methodological approach for the study; Section 4 provides a mapping of IS initiatives in Europe and discusses its main characteristics; section 5 discusses barriers, drivers and challenges for IS in Europe, while section 6 highlights potential areas of contribution of IS to CE strategies in the manufacturing sector. Finally, section 6 draws conclusions and outlines areas for future research. 


\section{IS ACTIVITY IN EUROPE: FINDINGS FROM THE LITERATURE}

A literature review of IS in Europe reveals three main streams of contributions around IS: 1) the first stream of contributions relate to the reporting and review of case studies of IS in Europe; 2) the second main stream relates to contributions to the development of assessment frameworks for IS activity; 3 ) the third key area of research addresses main drivers and policy interventions for IS, including comparative analyses.

Departing from the Kalundborg case study, often referred to as model of IS networks (Jacobsen, 2006), recent years have seen the 'unveiling' (Chertow, 2007) and reporting of IS case studies as examples of strategies for increasing resource efficiency and resource recovery. Industrial symbiosis activity in the Nordic region was mapped in the 2015 report 'the potential of industrial symbiosis as key driver of green growth in Nordic regions'. This report includes references to institutional arrangements, policies and economic structure conditions driving adoption of IS solutions. The report points at different types of strategic patterns ranging from top-down pro-active policies in Denmark and Finland to more bottom-up business driven approaches in Iceland, Norway and Sweden. EC's funded research projects have also reported progress of IS implementation in Europe. Evans et al. (2016) gathered a database of industrial symbiosis case studies and linked exchanges as part of the EC H2020 funded project MAESTRI 'Energy and resource management systems for improved efficiency in the process industries'. The database registers 46 case studies reported in the literature, 35 of which correspond to analysis of EU based networks in 6 EU countries, Italy, Sweden, UK, Germany, Denmark and Portugal. UK and Italy register most of the cases as examples of facilitated synergies by NISP and NI IS in the UK and ENEA in Italy. Another EU funded project on eco-innovation included a survey on eco-innovation initiatives in Europe and internationally (Sofies, 2014). The survey registers 116 initiatives in Europe though the scope is wider than IS network and ecoindustrial parks to also encompass other green initiatives both at urban and industrial parks (e.g. technology parks, green businesses, etc.). A number of other contributions have reported incipient IS activity in specific regions and industrial areas or have attempted to identify unrealised potential for IS. Taddeo et al. (2012) analyse a chemical cluster in the the Abruzzo region, in Italy, to understand existing and potential IS opportunities. The study unveils some IS kernels through exchanges of unreacted silica sand and recovery of spent sulphuric acid and cascading of steam and mineralised water but also points at other areas and opportunities where IS projects could generate economic and environmental benefits. Similarly, Simboli et al. (2014) explore the potential for IS in a motorcycle cluster in Italy. The study unveils inefficiencies in the current waste management of main waste streams and proposes collective management of metal scraps and the creation of a disassembly and recovery local network as potential solutions.

Linked to the above, another key stream of literature has focused on the development of frameworks to IS activity, both conceptually and assessment-based. Boons et al. (2011) proposed a conceptual framework for IS activity. Their conceptual framework contributes to shed insights on the dynamics of IS. The authors distinguish three main interacting dimensions which encompass: 1 ) the antecedents of the networks, from industrial structure to types of business organisation, 2) the mechanisms for promotion and adoption of IS and, finally, 3) the assessment of societal, environmental and economic outcomes. The authors conclude with a research agenda for a better understanding of the role of institutional conditions and trigger mechanisms for IS. Taddeo et al. (2017) present a framework to understand the evolution of IS in traditional industrial clusters and the technical and non-technical factors that play a role in the promotion of IS solutions. The proposed framework takes into consideration: 1) the geographic and technical specificities of the cluster; 2) level of heterogeneity of the network; 3 ) degree of participation of stakeholders; and 4) the regulatory system and combines it with a dynamic understanding of the development stages of the industrial cluster. Attempts to provide quantified assessment frameworks for IS have also been undertaken. Martin (2014) proposes the use of a life cycle approach for the quantification of IS benefits. The method is tested in 
the area of biofuel production, showing potential of IS to reduce the environmental burden and costs associated to biofuel production.

The other main key stream of work focuses on policies and approaches to promote or favour the emergence and development of IS solutions. Despite paradigmatic cases such as Kalundborg, a key question that remains unanswered is why advances in IS implementation in Europe are proven timid and slow. IS literature has tried to answer that question by looking at drivers and barriers to promote IS. Based on analysis of European based case studies, Taddeo et al. (2012) provides a summary of main barriers to IS concluding that IS activity is constrained by regulatory and legislative barriers, but also financial obstacles and lack of 'on the ground support' to IS projects. Zander et al. (2016) study the emergence of cooperation in the wood industry in Germany. While the focus is wider than IS cooperation, encompassing any cooperation for sustainability, the contextual factors contributing to network governance are not dissimilar to others discussed in IS literature such as trust, exchange of knowledge and information and geographical proximity. Costa et al. (2010) discuss key factors in the development of industrial symbiosis highlighting the role of enabling policy frameworks and of adequate waste policies which incentivise efficient use of underutilised resources. Costa and Ferrao (2010) highlight the role of the policy framework to enable a process of interaction between stakeholders and aligning strategy and policy action, combining top-down and bottom-up initiatives, to support the emergence and development of IS. Similarly, Paquin and Howard Grenvillen (2011) differentiate between serendipitous and goal-directed network processes in IS development. Serendipitous processes can generally be observed in the initial stages of self-organised networks. In these cases, network benefits and economic drivers are strong and firms have easy access to one another and cooperate to create value. The pace of development though may be slow and, generally geographically constrained; On the other hand, Goal-directed network processes may accelerate the expansion of the network through alignment of strategies. Both processes may play different roles at different stages in the evolution of networks.

The literature review reveals that while numerous case studies analysis which assess the structure, conditions and performance of IS initiatives in Europe exist, an overall updated overview of IS activity in Europe is still missing. This paper aims to contribute to this by providing a descriptive mapping of IS in Europe and identifying key characteristics of IS networks in Europe. The paper also points to key drivers and obstacles of IS activity in Europe. Section 2 presents the methodological approach for the study; Section 3 provides a mapping of IS initiatives in Europe and discusses its main characteristics; section 4 discusses drivers and challenges for IS in Europe, while section 5 provides highlight potential areas of contribution of IS to CE strategies in the manufacturing sectors and points to elements that still need addressing to maximize its contribution. Finally, section 6 draws some conclusions and suggests areas for future research.

\section{Methodological notes}

The paper reports the findings from a EC funded project "Cooperation fostering industrial symbiosis: market potential, good practice and policy actions" (act No 409/PP/2014/FC Lot 3), which main focus is to provide an overview and assessment of IS activity in Europe. Data was gathered through a combination of secondary and primary data sources. Primary sources included: a) an online survey to existing IS facilitated networks in Europe $(n=22)$, which was addressed at a strategic sample of network coordinators and IS practitioners who act as facilitators including both private and public organisations and PPPs_previously contacted by phone, b) in-depth interviews $(n=25)$ with key stakeholders, including IS network facilitators and coordinators as well as policy makers and civil servants working in the area of IS and related policies and c) finally, three focus groups were conducted in London, Brussels and Rotterdam with representatives from industry, IS network 
coordinators and policy-makers. All primary data, including the survey, interviews and focus groups, was collected between March to September 2018. The design of the survey covered the following topics: 1 ) characterization of the network, including structure, funding and activities offered; 2 ) network participants and sectors of activity represented; 3) Types of resources exchanges; 4) impact of the network (e.g. landfill diversion, CO2 savings, etc.); 5) drivers and obstacles for IS; 6) the role of facilitation and 7) enabling policy frameworks for IS. Similarly, in-depth interviews revolved around a similar set of topics, but provided further flexibility to elaborate on the key drivers and obstacles faced by IS networks and the discussion in some depth of policy approaches to promote IS in Europe. All interviewees had practical experience in the field of IS either from the facilitation or policy-making side. Interviews were conducted face-to-face or by-phone (conference call). Finally, the focus groups, organized in the three cities discussed main obstacles to upscale IS initiatives and different policy mixes and areas where EU coordinated action could add value to promote IS. Additionally, a review of case studies based on the combination of both desk research and primary information gathered through the survey and interviews, was undertaken to identify main characteristics defining the dynamics of IS, typologies of network, content of the transactions and scale of influence of IS networks in Europe. Figure 1 summarizes key aspects of the methodological framework. Main sources of primary data relied mainly on facilitated initiatives, where there was a third party coordinator. There are some limitations to the methodological design adopted. Findings from the survey thus mainly reflect drivers and obstacles to IS from the coordinator/ facilitator point of view which may differ from the drivers and obstacles perceived and experienced by firms and other types of IS networks (e.g. selforganised networks). The focus groups partly addressed this issue, by including participants from the private sector among other stakeholders as well as representatives from self-organized activity. 
Figure 1: research design and data sources

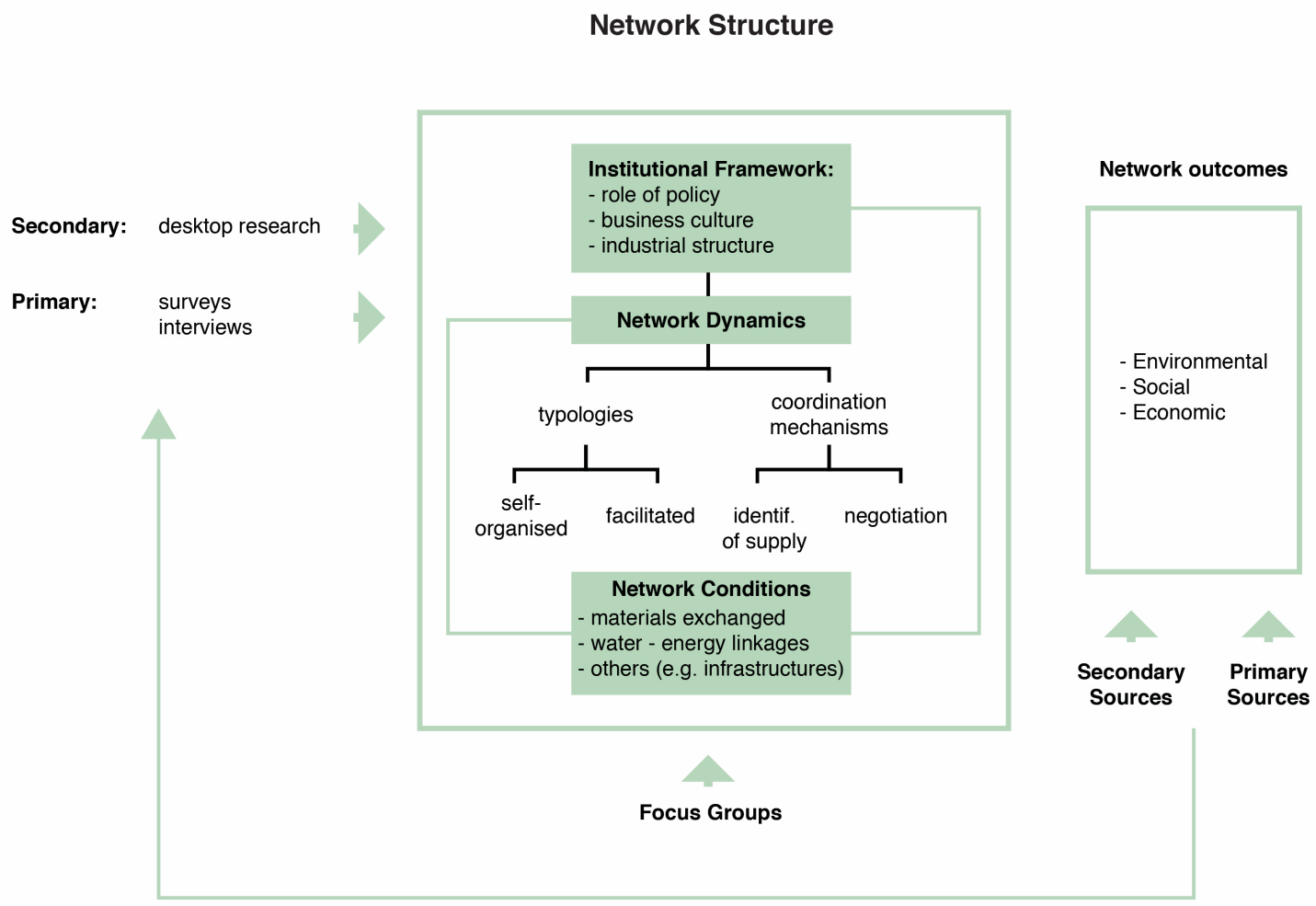

Source: Authors' elaborated

\section{Findings: OVERVIEW OF IS DEVELOPMENTS IN EUROPE}

\subsection{Mapping IS developments in Europe}

The mapping exercise suggests a number of differentiated patterns of IS networks in Europe. Figure 2 summarises key characteristics of established networks in Europe. Table 2 in the appendix I, provides further detail of the mapped networks. 
Figure 2: Mapping of IS networks in Europe

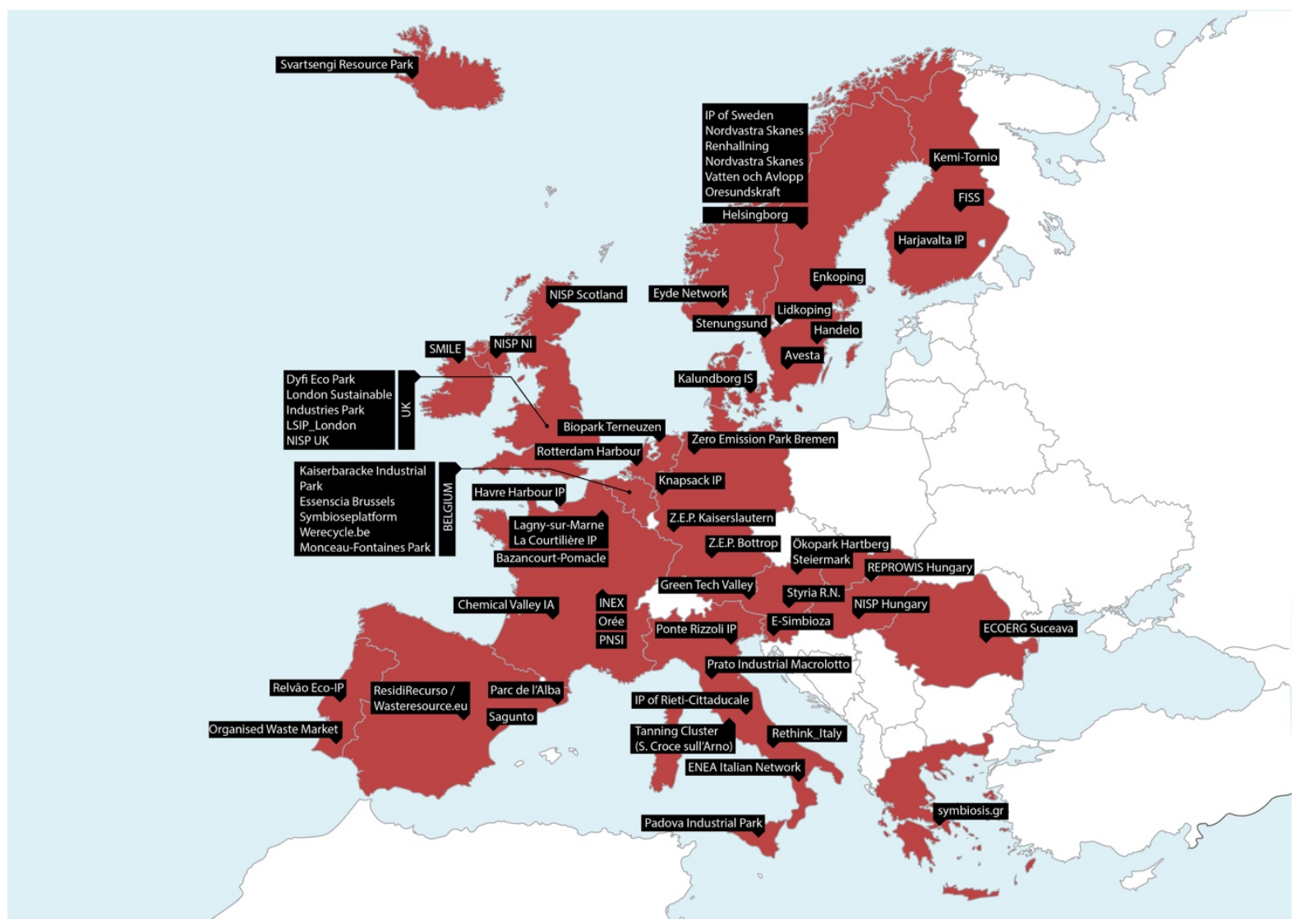

Source: authors elaborated

The mapping suggest that IS activity in Europe is very diverse in terms of its nature, emergence, development patterns and content of the transactions. Geographical scope and coordination mechanisms vary across initiatives. The sections below discuss key characteristics of IS in Europe. The mapping exercise has mainly relied on information from 'formalised' networks, those networks that report activity in the area of IS, whether it is self-organised, planned or facilitated. However, as acknowledged previously, it is likely that pockets of IS activity are happening in other manufacturing and industrial clusters throughout Europe. The mapping, where possible, also considers IS activity 'unveiled' in the literature which is undertaken spontaneously by manufacturing activities. See, Wolf et al. (2007) for the wood-paper industry in Nordic countries or Domenech and Davies (2010) for steel and construction material cluster in Sagunto (Spain). However, further research is needed to map other IS activity in manufacturing clusters in Europe.

\subsection{Typologies of networks}

The literature, generally, classifies IS activity into two main groups: 1) self-organised activity, emerging as the result of direct interaction among industrial actors; 2) facilitated networks, those that have a third party intermediary who coordinates the activity (Baas, 2011) and 3) planned networks, which result from a central plan or vision, generally for a specific industrial area, which includes shared infrastructures and services and coordination/ promotion of IS exchanges.

The mapping exercise undertaken in this research identified examples of IS activity following the three typologies mentioned above. Most of the examples of self-organised networks come from Northern countries and date back to the 1960s or earlier. Among, self-organised networks, the case of Kalundborg is generally refer to as a model for IS. IS 
activity was initially motivated by scarcity of freshwater for the manufacturing sector in the area and driven by economic gains and cost-saving opportunities, generally linked to common development of infrastructure. Reuse of waste heat, steam and energy created additional opportunities for companies to deepen collaboration. It is also important to note that most companies in the initial Kalundborg network were and still are sustainability leaders in their sectors and there was an open dialogue between CEOs on business sustainability issues coordinated through an informal social network (Domenech and Davies, 2011).

Building on the experience of Kalundborg and widespread adoption of district heating networks, a number of eco-industrial park initiatives and IS networks have been established in Scandinavia and neighbouring countries. They tend to have a strong focus on reutilisation of waste energy and heat through combined heat and power (CHP) systems, district heating networks and other opportunities to reutilise waste heat. Specific instruments have been put in place to favour these types of synergies. In Sweden, for example, the local investment plans (LIP) and the Climate Investment Programme (KLIM) have funded IS projects. The programmes' aims include promoting ecologically efficient systems, increasing the reuse of energy and material resources and improving circularity of nutrients. Local authorities are invited to develop local strategies in collaboration with local stakeholders in projects that generally have a 3-4 year span. LIP and KLIM generally provide $30 \%$ of funding for physical infrastructures (eukn, n.d.) ${ }^{1}$ and have contributed to fund projects in Händelo and Lindberg, where waste heat of a cardboard mill was sent to a district heating network.

IS initiatives in key sectors such as forest industry and paper, chemicals, metals, mining and construction materials have also developed in several regions. Examples of IS activity between the wood and pulp and paper sectors in countries like Sweden and Norway are common. In an analysis of the forest industry in Sweden, Wolf and Petersson (2007) found that over one-third of the Swedish forest industry investigated in the study maintained IS transactions with neighbouring companies, involving energy, heat and material exchange. Monteras network is an example of this (Baas, 2011).

From the analysis, self-organised networks seem to share some commonalities: 1 ) they operate at the industrial estate level or local level; 2) they are generally linked to a clustering of manufacturing activities, with some primary sectors involved; 3) they have emerged as business-as-usual transactions in countries where social licence to operate is shaped by higher environmental awareness and more stringent environmental regulatory frameworks; It is also common to be driven by private actors but with with local government support and participation. Networks such as Kalundborg (Denmark), Harjavalta (Findland), Landskrona (Sweden), Kemi-Tornio (Findland) and Handelo (Sweden) follow this pattern.

Styria is another example of a long-standing self-organised network. Some coordination mechanisms have been developed over the years to promote further development of the network, however, most of the recycling/by-product activity is developed as bilateral market transactions (Posch, 2010). Styria in Austria sits in a large manufacturing cluster and the 'Green Tech Valley' and covers activities ranging from agriculture and food processing; wood, metal, paper, textile and plastic industries; and energy production. Selforganised IS activity has also been reported in the chemical clusters in Germany.

There is also evidence of IS activity that has developed in traditional manufacturing clusters as a consequence of the introduction of more stringent environmental regulation. Domenech and Davies (2011) report IS activity in a metal/cement cluster in Sagunto (Spain) driven by the introduction of stricter water, waste and air emissions regulation.

Facilitated networks and planned initiatives have also been developed across Europe. NISP UK is perhaps the most cited example of facilitated model for which there was

\footnotetext{
${ }^{1}$ See http://www.eukn.eu/e-library/project/bericht/eventDetail/local-investment-programmes-lip-and-climateinvestment-programmes-klimp-1-1-can-be-3/
} 
monitoring of benefits achieved. NISP reported 45 million tonnes of waste diverted from landfill, 39 million tonnes in $\mathrm{CO}_{2}$ savings, 58 million tonnes of virgin raw materials saved and cost-savings for industry of $€ 1.21$ billion over the period 2005-2013 (NISP, 2013). The facilitation model adopted by NISP has been replicated in other regions under different funding structures.

An example of a long-standing facilitated network in Europe is the IS Northern Ireland (previously NISP NI), funded by the business development agency Invest Northern Ireland. The programme, which is based on the NISP model, celebrated its tenth anniversary in 2017. IS NI has reported cost savings of around $£ 9$ million, additional sales of $£ 13.5$ million and private investment of $£ 1.88$ million since 2007 . It diverted 392,000 tonnes from landfill and contributed to $\mathrm{CO}_{2}$ reduction of 261,510 tonnes (Invest Northern Ireland, 2018). NISP Scotland (previously SISP) was initiated in 2007, also following the NISP model. The programme reported 312,295 tonnes of landfill diversion, 194,183 tonnes of $\mathrm{CO}_{2} \mathrm{e}$ savings and costs savings to industry of around $€ 4.65$ million from 2007 until its termination in 2012 (NISP, 2013).

Other facilitated initiatives have been launched in Europe in the last decade. They have different geographical scopes and are inspired by different facilitation models. Most of new facilitated activity has concentrated in eastern European countries (such as Poland, Hungary, Romania, Slovakia and recently Slovenia), with other relevant examples in northern and central Europe (Belgium, France, Denmark and Finland) and southern Europe (Italy, Spain).

Some of them have been active for a short period of time, linked to a project and specific funding stream (Life+, SPIRE, H2020, INTERREG and other European, regional and national funds), but have not managed to transition towards commercial models after funding has ended. Examples of this include programmes in Poland, Hungary, Romania and Finland. In the case of Hungary, Finland and Denmark potential follow-ups of the programmes are currently under discussion or awaiting budget approval.

Example of planned networks, can also be found in different areas in Europe. They generally take the form of eco-industrial parks or brownfield regeneration projects. The London Sustainability Industries Park (UK), in Dagenham Dock (London), is an example of top-down initiative to foster the regeneration of the industrial area part of the London Green Entrepreneurial District, initially led as part of the Thames Gateway Development Corporation and subsequently by the Borough of Barking and Dagenham and the Greater London Authority (GLA). The vision of the development dates back to 2005 and tried to foster a cluster of clean technologies that would take advantage of its location to transform waste streams from the city of London back into resources. Despite a slow start, construction work was completed in 2012 and the area has attracted multi-million facilities in the area of waste management and recycling, including a closed loop plastic recycler, a gasification plant and two AD bio reactors. Also in the UK, a small initiative with a focus on the provision of energy efficient business units is Dyfi Eco-industrial park in Wales. In Germany there have been a number of different initiatives to build Zero Emissions Parks in Bolton, Bremen and Kaiserslautern. In Portugal the Relvao industrial park was developed as a PPP to encourage the revitalisation of the area and the clustering of activities around the recycling and recovering of different types of materials including plastics, biomass, sanitary waste and textiles (Costa and Ferrao, 2010). Attempts to foster IS networks through planned initiatives can also be found in Central Europe, such as Ecopark Terneuzen, in The Netherlands, and in the South of Europe, such as Parc d'alba and the planned eco-industrial Torrent Estadella both in Catalonia (Spain) or the ecologically equipped industrial areas in Italy in the Marche region in Italy.

\subsection{Geographical distribution and scope}

The mapping reveals pockets of IS in different regions throughout Europe. As discussed above, northern and central Europe concentrate most of the examples of self-organised 
IS. However, the analysis also demonstrates that bi- and multi-lateral activity is common in manufacturing clusters across Europe, in many cases linked to more stringent regulation and incentives to divert waste from landfill. Attempts to replicate opportunities through facilitated networks have also developed around Europe, including eastern European countries and southern Europe. Performance of these initiatives varies considerably and will be discussed in more detail in the next section. Planned initiatives, generally at a local scale, have taken in most cases the form of eco-industrial park developments and ecologically equipped zones.

When looking at the geographical scope of the networks, this also varies considerably across typologies of networks. Self-organised networks tend to have a local scope. Most core members generally involve neighbouring companies, although, in some cases, transactions may go beyond network boundaries, depending on: 1) the type of waste stream/by-product; 2) transport costs and 3) market value of secondary materials. Planned networks are also predominantly local, as they generally include the sharing of infrastructures and services. Facilitated activity have demonstrated that can work at different scales with National programmes, such as the former National Industrial Symbiosis (NISP), in the UK, and programmes in Hungary, Finland, France or Denmark which have tried to promote IS synergies nationally, in many cases complemented by regional initiatives or programmes (following the methodology of the UK NISP).

The scale of IS networks is dependent upon: 1) information flows with regards to types of waste/by-products produced by other companies/facilities; 2) understanding of opportunities derived from IS transactions and 3) know-how and resources for implementing the IS synergies. These elements require a degree of collaboration among businesses to favour communication and willingness to find collective solutions. These elements are likely to emerge spontaneously between companies which are co-located, but less likely to happen when activities are not co-located unless there is a third party which acts as coordinator and centralises information to identify opportunities. Another key factor influencing the geographical scale of networks is transaction costs, which include not only transport costs but also intermediation and negotiation costs. This is very relevant in the case of IS, where marginal value of the waste streams tends to be low or even zero or negative in some cases (e.g. C\&D waste).

\subsection{Types of waste streams and distance}

Types of waste streams exchanged in the network are dependent on the sectorial composition of the network. Among main resources reported in the survey, which are common to most networks, are chemicals (e.g. chemical base products), biomass and agriculture by-products, wood and wood pellets, plastics, reusable construction materials, equipment, inert waste and then water (different qualities including industrial water), residual heat and steam.

Interviewees and focus groups have highlighted that the role of distance is highly dependent on the resource type, with different resource having substantially different radius for IS activity. Qualitative findings from this research, suggest that the geographical scope for different types of resources depends on: 1) type of waste stream and its physical and chemical characteristics; 2) value of the waste stream and 3) geographical distribution of resource recovery facilities. In general terms, bulky low value waste, such as construction and demolition (C\&D) waste, tends to be restricted to local (city/ metropolitan area) transactions, while low volume high value resources, such as cobalt, may have an international market. Steam and waste heat exchanges are necessarily restricted to the local level, as they cannot be transported over long distances. Common metals such as steel and aluminium are generally traded in local/regional markets while more valuable and scarce metals and minerals can travel considerable distances, as shown in Figure 3. 


\section{Figure 3: Types of resources traded by area}

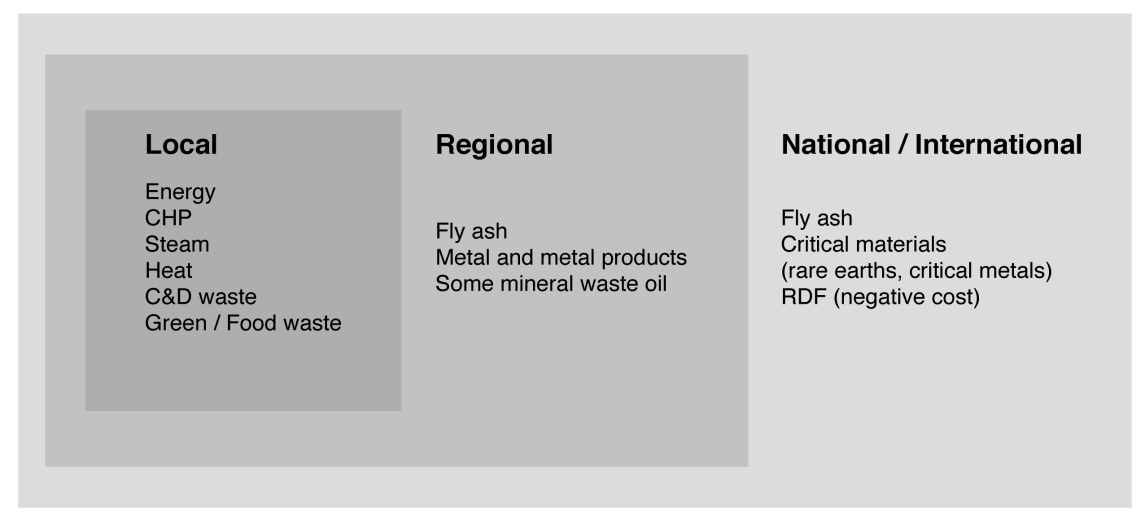

Source: Authors' own elaboration as part of EC project "Cooperation fostering industrial symbiosis: market potential, good practice and policy actions".

Although, empirical research in this area is scarce, these findings seem to be in line with Jensen (2016), which explores the role of geographical distance and industrial diversity as key variables influencing travel radius of resources exchanged. Jensen (2016) found: 1) high correlation between area of industrial activity and presence of completed synergies; 2) distance travelled by resources was an average of $34 \mathrm{~km}$; 3 ) synergies where the distance was greater than $34 \mathrm{~km}$ tend to occur in areas with lower geospatial diversity (Jensen, 2016). Similarly, Velenturf and Purnell (2017), based on a case study in the Humber region (UK), concludes that: 1) most companies can identify potential users of their resources and by-products from direct contacts and 2) that $73 \%$ synergies tend to happen within a $75-$ mile $(120 \mathrm{~km})$ radius. Findings from the mapping and survey seem to align with these results, also demonstrating that self-organised IS activity is present in manufacturing clusters across Europe, and density of transactions tend to diminish with distance.

\subsection{Size of networks}

Size of networks also differs considerably across initiatives in Europe. Variation tends to happen depending on the geographical scope of the network. Regional/national networks naturally tend to have a higher number of members while local networks tend to be smaller in size (measured by number of members but also volumes of transactions). Networks included in the mapping exercise, for which there is data, had an average size of 473 members, but the median is approx. 100 members, which indicates the variability of sizes and significance of networks with local scope. Comparing network size and number of synergies does not seem to follow a linear patter, as some networks seem to be more successful in recruiting members and forging synergies between them. While previous research (Jensen, 2016) found high correlation between the size of the network, diversity of sector/activities and number of transactions, the scope was restricted to data from NISP regional programmes, which all followed a harmonised framework of implementation and quantitative reporting of synergies. In here, the wider scope of this study, which includes different typologies of networks (self-organised, facilitated and planned), makes the comparison between size and performance more complex, as other factors surrounding the structure of the network and its scope seem to play a role. Data gaps and lack of harmonised quantitative indicators limit the analysis and the ability to derive ultimate conclusions regarding the role of the size in network performance. The question whether larger networks (with more members) are more successful in promoting synergies than local, closely-knitted networks, such as Kalundborg, remains unanswered. One may argue that there may also be a trade-offs between the size of the network and the ambition and complexity of the project they embark with. Domenech and Davies (2011), suggest that 
closely-knitted networks can lead to embeddedness favouring initiation and development of IS synergies. Facilitation models have tried to reproduce embeddedness mechanisms in larger networks. From the review of networks in Figure 2 (and table II in Appendix I), the performance of the network in terms of number of synergies and reported impact does not necessarily seem to correlate with the number of members in the networks. Nevertheless, the lack of standardised measures of the performance of networks constitutes a main obstacle in establishing the role of size and diversity in the realisation of synergies.

\subsection{Key sectors}

In terms of key sectors, there is also considerable variation. Figure 4 reflects findings from the survey in terms of representation of sectors of activity in facilitated networks and highlights the relevance of manufacturing activities. In terms of specific activities within the manufacturing sector, primary sectors such as pulp and paper, power production, metal, mining and construction materials tend to play an important role in IS networks, acting, in many cases, as anchor tenants of the network (see, for example, Kalundborg, Monteras and the chemical clusters in Germany). However, a characteristic of IS networks is the diversity of sectors involved and the opportunities created across activities and supply chains. Sectors such as waste and water management and recycling are also important players in IS networks. 


\section{Figure 4: Main sectors represented in IS networks}

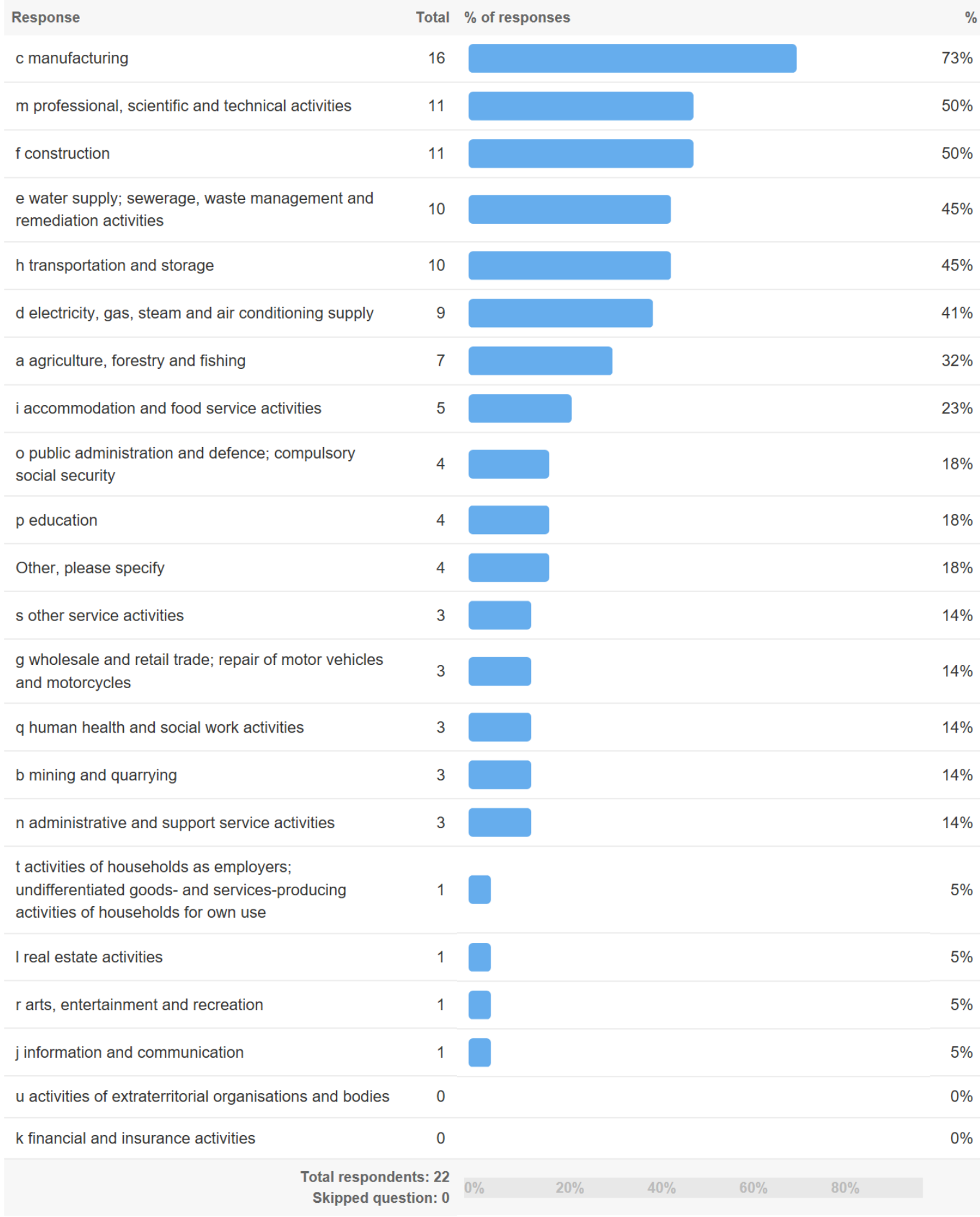

Source: Authors' own elaboration as part of EC project "Cooperation fostering industrial symbiosis: market potential, good practice and policy actions".

Diversity, which was also found to be a crucial factor promoting IS according in Jensen (2016), has been stressed in the interviews for the networks investigated as playing a primary role in developing successful synergies. Table II in Appendix I provides further detail of sectors represented in the different networks included in the mapping. 


\subsection{Economic, environmental and social benefits}

The survey to IS networks reported economic, environmental and social benefits associated with IS activity (see Figure 5 ). In most cases, the networks report resources exchanged and $\mathrm{CO}_{2}$ savings associated with IS activity as main environmental benefits. On the economic and social side, most networks report costs savings and other additional benefits such as jobs created and safeguarded and new revenue streams. Thus, IS can deliver numerous co-benefits towards a low carbon development as proposed by the IPCC.

Figure 5: Key economic, social and environmental impacts of IS

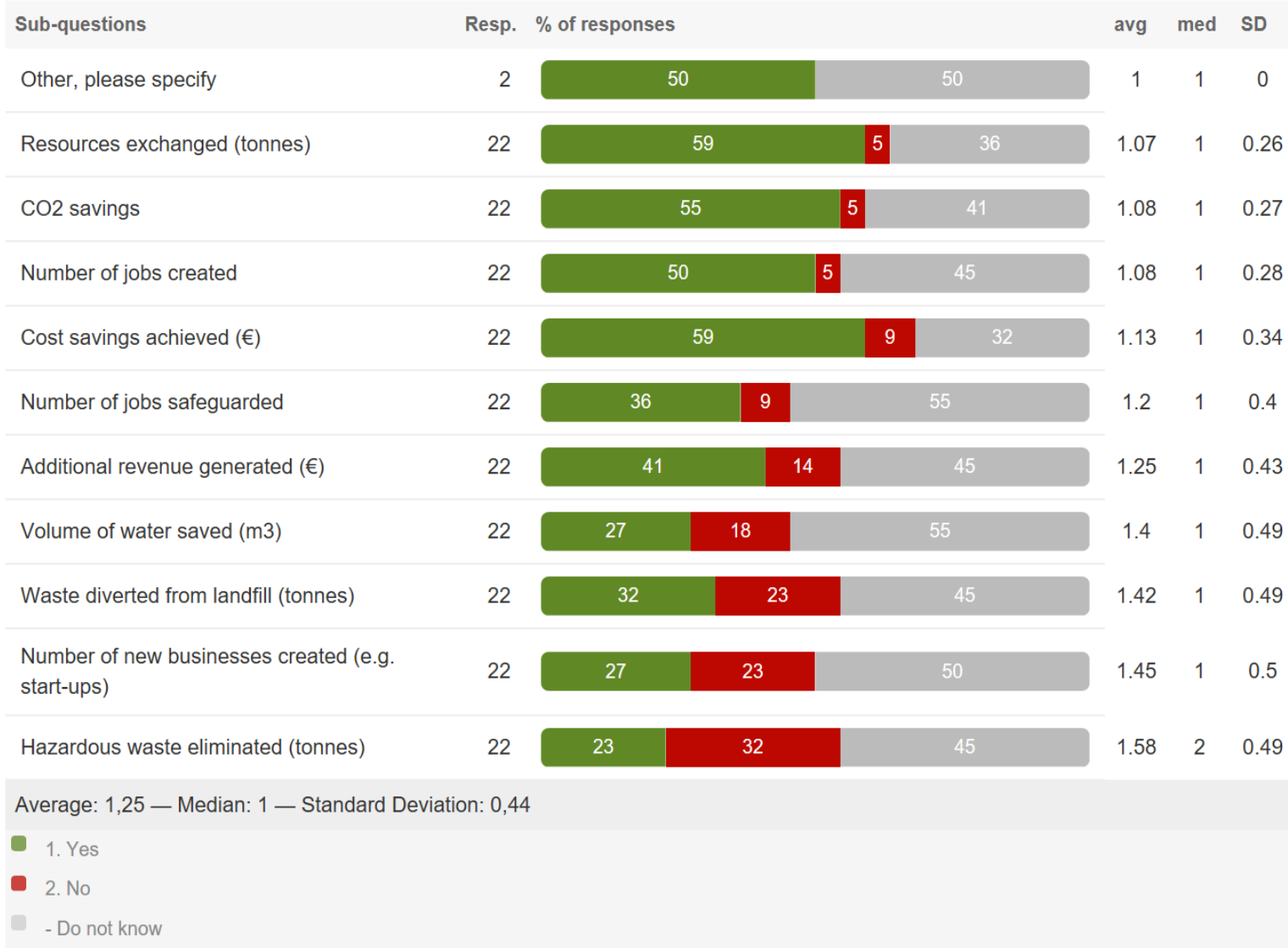

Source: Authors' own elaboration as part of EC project "Cooperation fostering industrial symbiosis: market potential, good practice and policy actions".

As mentioned above, the mapping exercise has identified important data gaps in the way IS networks are monitored and evaluated. Figure 5 also highlights by the big \% in grey lack of accountable data for the monitoring of impact of IS networks. Very few studies and initiatives have provided quantification of IS benefits in Europe (Karlsoon and Wolf, 2008; Van Berkel, 2010; Sokka et al., 2011). Quantification methods have used a combination of tools from the industrial ecology field and have generally been applied to regional or local networks. Wolf and Karlsson (2008) use an optimisation method to assess reduction of GHG associated to IS compared to standalone activity in the forest industry, covering the activity of a pulp mill, paper mill and biofuel production. Van Berkel (2010) and Jacobsen (2006) use direct estimation of benefits associated with IS activity for Kalundborg. Following Van Berkel (2010), the quantification may refer to three different processes that may occur through the synergies: conversion, substitution and avoidance. Conversion refers to processes related to transforming a previously-wasted material, 
water or energy from its source to its treatment and processing to be transformed into a suitable feedstock. The substitution process refers to substitution of original (virgin) stock by a secondary source and adjustments of processes/quantities if required to compensate for the lower grade of the resource and, finally, avoidance processes that refer to the elimination or reduction of disposal costs. NISP developed possibly the most comprehensive method of monitoring impact in Europe based on identification of realised benefits across a number of social, economic and environmental indicators. NISP monitoring system has been adopted by other facilitation initiatives in Europe that have followed the NISP model. Table 1 includes main impacts reported by facilitated activity in Europe.

Table 1: Reported Impact of Facilitated IS Networks in Europe

\begin{tabular}{|c|c|c|c|c|c|c|c|}
\hline & NISP Scotland & NISP Hungary & NISP UK & $\begin{array}{l}\text { Romania } \\
\text { ECOERG }\end{array}$ & Invest NI & PNSI & SMILE $^{\star \star \star}$ \\
\hline Period & 2007-1011 & 2010-2012 & 2005-2012 & 2009-2011 & $2007-2017$ & $2015-2017^{*}$ & 2016-2017 \\
\hline Network size & & $800+$ & $15.000+$ & $200+$ & $1.900+$ & $588+$ & $1.581+$ \\
\hline $\begin{array}{l}\text { Number of } \\
\text { synergies } \\
\text { (realised) }\end{array}$ & 127 completed & 72 completed & & 200 synergies & 448 & 958 potential & 1.882 potential \\
\hline Scope & regional & $\begin{array}{l}\text { regional / } \\
\text { national }\end{array}$ & $\begin{array}{l}\text { regional / } \\
\text { national }\end{array}$ & $\begin{array}{l}\text { regional / } \\
\text { national }\end{array}$ & national & $\begin{array}{l}\text { regional / } \\
\text { national }\end{array}$ & $\begin{array}{l}\text { regional / } \\
\text { national }\end{array}$ \\
\hline $\begin{array}{l}\text { Landfill } \\
\text { diversion (t) }\end{array}$ & 62.459 & 594,16 & $6.428 .571,42$ & 265.000 & 39.200 & $13.954,5$ & 7.342 \\
\hline $\begin{array}{l}\text { GHG savings ( } t \\
\text { CO2) }\end{array}$ & $38.836,6$ & 1875,67 & $5.571 .428,57$ & 65.000 & 34.000 & $1.081,5$ & \\
\hline $\begin{array}{l}\text { Virgin raw } \\
\text { materials saved } \\
(\mathrm{t})\end{array}$ & & 619 & $8.285 .714,28$ & & 24.000 & 3.920 & \\
\hline $\begin{array}{l}\text { Hazardous } \\
\text { waste saved }(t)\end{array}$ & & & $285.714,28$ & & 1.270 & & \\
\hline $\begin{array}{l}\text { Water savings } \\
\text { (m3) }\end{array}$ & & $13.017,98$ & $10.142 .857,14$ & & & & \\
\hline $\begin{array}{l}\text { Cost savings } \\
\text { (Mill EUR) }\end{array}$ & 0,93 & & 172,85 & & 2,77 & 0,25 & 1,25 \\
\hline $\begin{array}{l}\text { Additonal sales } \\
\text { (in mill EUR) }\end{array}$ & 0,4 & & & & 1,79 & 3,47 & \\
\hline $\begin{array}{l}\text { Private } \\
\text { investment (in } \\
\text { mill. EUR) }\end{array}$ & 1,602 & & 243 & & 0,211 & 0,037 & \\
\hline Jobs (number) & & & & & & 3 & \\
\hline $\begin{array}{l}\text { Total Budget (in } \\
\text { mil. Euros) }\end{array}$ & 0,256 & 0,396 & 6,341 & 0,4403 & & & 0,15 \\
\hline
\end{tabular}


nical support. Budget is approx. $€ 150,000$ per year and about $€ 600,000$ in total. Here the calculations are based for 2016-2017 where there was technical support (comparable to the rest of the networks considered)

Source: authors compiled as part of EC funded project "Cooperation fostering industrial symbiosis: market potential, good practice and policy actions".

In most of the mapped cases, however, networks do not have any monitoring framework in place and lack harmonised mechanisms of data collection and quantification of benefits. Opportunities exploited through the network are largely unquantified, although generally, some general understanding of areas of benefits are perceived by members and facilitators. This happens across all categories of potential benefits (environmental, social and economic). This has been confirmed by the survey and interview findings, suggesting substantial economic, environmental and social benefits associated with IS activity, which go largely unreported for a number of different reasons, such as resistance of companies to provide data, lack of coordination mechanisms that collect and maintain the data and lack of technical capability and time to analyse the data. Benefits include costs savings linked to reduced waste and environmental management costs but also savings in sourcing of primary materials. This is consistent with the information collected for the few data points where information exists, and include both spontaneous and facilitated networks. Some examples of benefits reported by self-organised activity are summarised in Table .

\section{Table 2 Benefits reported by self-organised networks}




\begin{tabular}{ll} 
Network & Benefits reported \\
\hline Kalundborg & 2 million cubic meter/year ground water saved; \\
Source: Jacobsen & 1 million cubic meter/year surface water saved; \\
(2006) & 200,000 t natural gipsum saved \\
& 200,000 t fly ash used as secondary material \\
& 2,800 tonnes of sulphur saved \\
& \\
Styria Network & approx. 1 million tonnes of by-products gathered, 780,000 tonnes \\
Source: Posch (2010) & recycled, 200,000 tons landfilled or incinerated; 25,000 tonnese handed \\
& to professional waste management. \\
& \\
& Further, 330,000 tonnes were further identified as potential secondary \\
& materials \\
& $70 \%$ recycling rate \\
& $42 \%$ CO2 emissions saved \\
& $25 \%$ of final energy consumption from renewable sources
\end{tabular}

\begin{tabular}{|c|c|}
\hline $\begin{array}{l}\text { Harjavalta } \\
\text { Source: Nordregio } \\
(2015)\end{array}$ & $\begin{array}{l}\text { Long-term waste management: } \\
\text { waste from process (iron cake, etc): 19,000 t/y } \\
\text { hazardous waste: } 121 \text { t/y } \\
\text { Utilisation / special processes: } \\
\text { energy waste: } 351 \text { t/y } \\
\text { metals: } 181 \text { t/y } \\
\text { lead: } 83 \text { t/y } \\
\text { hazardous waste: } 124 \text { t/y } \\
\text { recycled paper: } 15 \text { t/y } \\
\text { household waste: } 16 \text { t/y } \\
\text { "Utilisation level": } 81.8 \%\end{array}$ \\
\hline $\begin{array}{l}\text { Handelo } \\
\text { Source: Martin et al. } \\
\text { (2014) }\end{array}$ & $\begin{array}{l}\text { Using an LCA based approach, Martin (2014) identifies benefits } \\
\text { associated with integration of bioethanol and biogas in Handelo and } \\
\text { associated exchange of by-products and waste materials. The analysis } \\
\text { quantifies a significantreduction of GHGemissions in the existing scenario } \\
\text { (pre-2009) compared to stand alone production and } 3 \text { scenarios point to } \\
\text { further opportunities derived from reutilisation of by-products and waste } \\
\text { streams for biofuel production. Savings can amount up to } 35 \% \text { reduction } \\
\text { compared to stand alone production. }\end{array}$ \\
\hline & $\begin{array}{l}\text { The analysis also shows potential for reduction of acidification, although } \\
\text { this depends on the system of reference adopted and a potential } \\
\text { negative trade-off with the eutrophication impact category. }\end{array}$ \\
\hline
\end{tabular}

Source: compiled by authors based on Jacobsen (2006); Martin et al. (2014); Posch (2010) and Nordregio (2015). 


\section{BARRIERS, DRIVERS AND CHALlenges}

The mapping and insights from interviews also suggested that Key drivers for companies to engage in IS networks are a combination of economic and environmental concerns, as shown in Figure 6. It is interesting to note the strengths of the economic drivers here.

\section{Figure 6: Key drivers for IS activity}

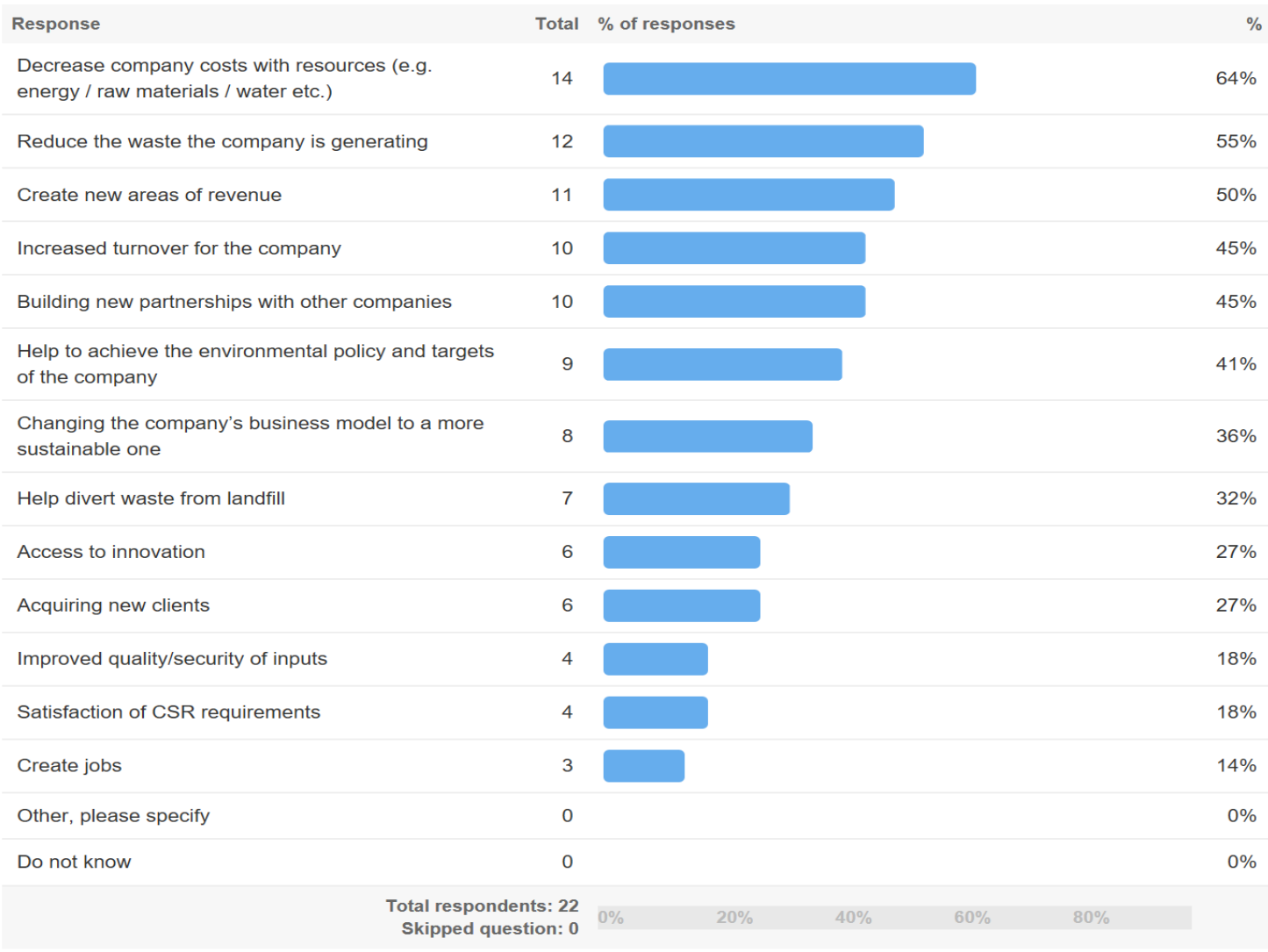

Source: Authors' own elaboration as part of EC project "Cooperation fostering industrial symbiosis: market potential, good practice and policy actions"

As highlighted in the interviews many of these drivers are closely connected with framework conditions and the role of policies shaping the playing field of economic actors. A number of facilitated and planned initiatives promoted by ad hoc policies and supported by PPPs and public investment have also had difficulties to continue operating as purely commercial programmes (e.g. NISP, UK or FISS, Finland). Although a lack of harmonized framework for measuring and reporting performance have resulted in the lack of quantitative indicators to measure IS activity impact, current initiatives seem to generate environmental benefits and cost savings, yet probably not at a scale that is feasible if such indicators existed.

Current difficulties to scale up IS activity are acknowledged in the interviews. Speaking of the complexity of realizing IS synergies one IS practitioner commented:

"(...even when there are potential matches....the success rate is around $10 \%$ due to the fact that there are many conflictual aspects. Main obstacles may include technical, logistic, regulatory issues; also, the companies may not have the time or resources to embrace the project or it's too expensive or simply they have not found the 
right company to make it happen. The regulatory issues however seem to be the most prominent ones. It would be much easier if the regulations could be more flexible (here referring to the concept of waste in current $E U$ legislation). The end of waste criteria has helped but there are still a lot of issues that remain".

Figure 7 shows main obstacles reported by IS facilitators in the survey. Obstacles range from risks and uncertainty issues linked to IS exchanges to lack of time (specially in the case of SMEs) and a range of transaction costs including transport and learning costs.

\section{Figure 7: Key barriers to IS}

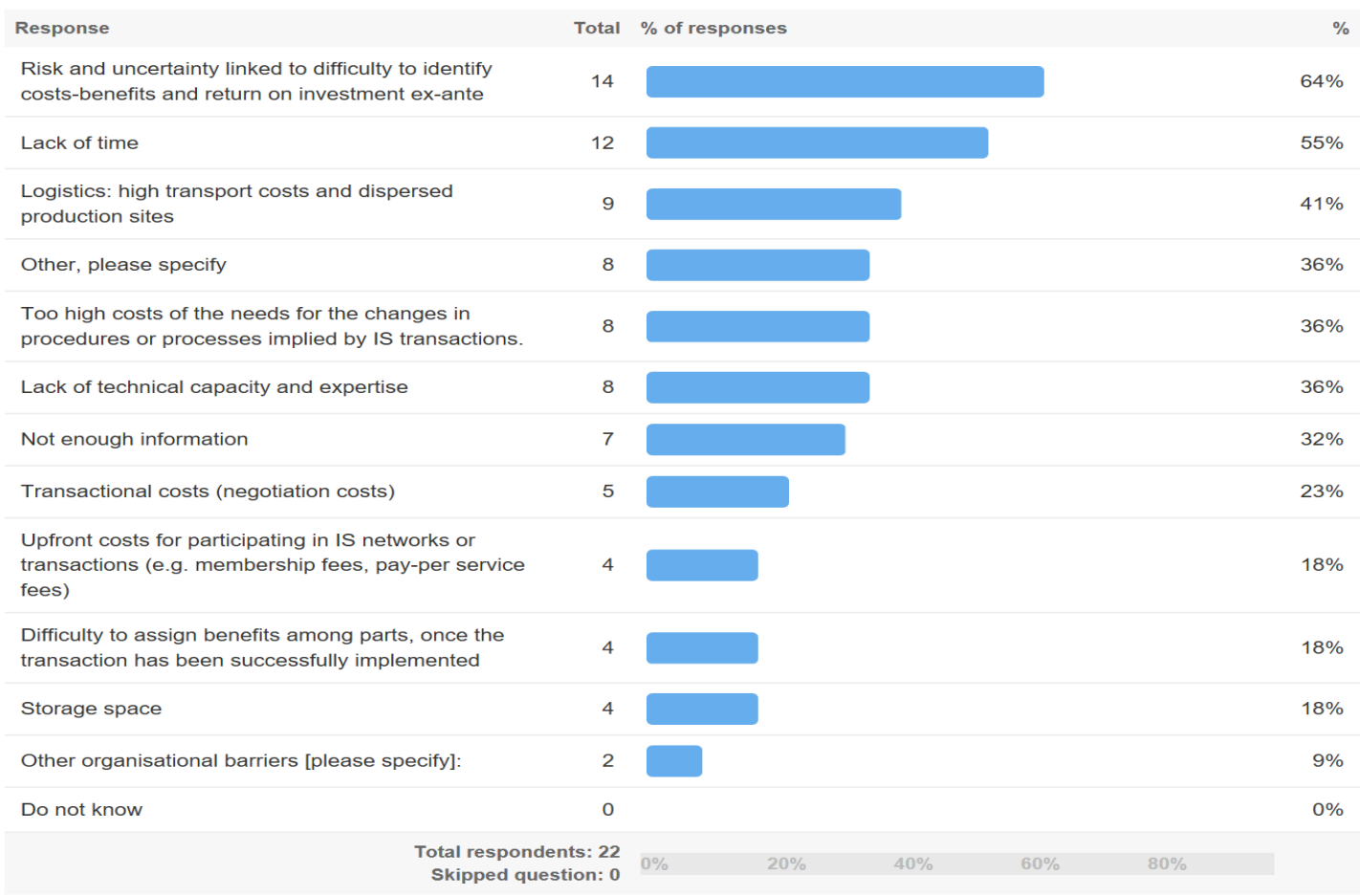

Source: Authors' own elaboration as part of EC project "Cooperation fostering industrial symbiosis: market potential, good practice and policy actions"

Tackling these main obstacles calls for novel ways to ease transactions, supported by integrated policy mixes that address main systemic factors negatively affecting the adoption of IS solutions in Europe. The interviewees referred to specific instruments such as policies to reduce $\mathrm{CO}_{2}$ and measures to promote landfill diversion (e.g. landfill tax) playing an important role in shaping the feasibility of IS projects. However, they also pointed at measures such as simplifying the process of acquiring end-of-waste criteria, harmonizing the legal definition of by-product, advanced assessment frameworks and cost-benefit analysis and other measures to ease transaction costs such as facilitated networks and resource knowledge IT systems as potential catalyzers to acceleration adoption of IS practices.

In here, learnings from pioneering policies in other parts of the world such as China (see, for example, Matthew and Tan, 2011, Jiao et al., 2018 and Su et al., 2013) and Korea (see, Behera et al., 2012) could help to identify favorable framework conditions, some of which could be adapted to the EU institutional framework and inspire areas of policy intervention. Some first steps in this direction have been promoted by the recently launched CE circular Economy package, which for the first time explicitly refers to IS as core strategy to promote circularity. 


\section{THE CONTRIBUTION OF IS TO PROMOTE CE IN THE MANUFACTURING SECTOR}

As mentioned above, IS has now been officially recognized as a practical approach to promote CE and is embedded in EU law through the final ratification of the EU CE package in July 2018. The new EU circular economy package refers to IS in connection to two main areas:

- As a way to increase circularity in production processes, through more efficient use of by-products, through clarifications in the definition of by-products and further harmonization of practices across MSs

- As a key theme of the innovation, investment and horizontal measures, through expanding the base of knowledge in $\mathrm{H} 2020$ projects and as part of R\&I investment for cohesion funds and policies

As part of the package, the revised legislative proposals have now included a revised Art. 5 of the waste framework Directive (WFD) to ensure that MSs take action to ensure 'that a substance or object resulting from a production process the primary aim of which is not the production of that substance or object is considered not to be waste, but to be a byproduct' when a number of conditions are met. Further clarification to achieve end-ofwaste status have also been added for waste that have undergone recovery processes.

These changes partly address the difficulties highlighted by interviewees stemming from the lack of legislative clarity about the status of industrial by-products and the criteria when a waste ceases to be a waste. It is still unclear, though, how the transposition of these revision to current waste legislative sector will impact the feasibility of IS projects in Europe.

The mapping exercise presented here, has unveiled three key areas where IS has played a role in contributing to a more circular manufacturing in Europe:

- Creating opportunities to increase the reutilization of components and materials through the use of by-products and waste to substitute primary raw materials. The survey pointed to different categories of resources exchanged through IS networks, preventing them to become waste, which included different types of chemicals, plastics, woods of different qualities, biomass, redundant stock, reusable construction materials but also water, steam and energy.

- Identifying ways to reduce structural waste through optimal utilization of underutilized resources and assets (including infrastructures, buildings and space). The study revealed that this was a common feature in eco-industrial parks and other planned activities but also common in networks composed by SME's such as the Tanning cluster in Santa Croce Sull'Arno, in Tuscany, reported by Daddi et al. (2016 and 2017), where SMEs share wastewater plant and other treatment facilities.

- Promoting projects to reduce overall volume of waste and emissions generated by manufacturing activities. Both Table 1 and Table 2 above report contribution of both self-organized and facilitated IS activity in Europe amounting to several million tonnes fo landfill diversion and GHG emissions saved.

However, for these opportunities to materialize and reach full potential, facilitation and direct support to IS initiatives through specific support mechanisms and policies, including increasing the costs of landfilling and incineration, is needed to enable action and to address key barriers to IS upscaling as discussed in Figure 7 above.

\section{Conclusions}

The research presented in this paper has focused on mapping the existing IS initiatives in Europe and identifying their key characteristics. The mapping indicates pockets of IS 
activity all across Europe, although varying in nature, resources exchanges and geographical scale. The mapping has revealed significant number of self-organised networks in Northern Europe, in countries like Sweden, Denmark or Finland, but also revealed activity in other traditional industrial clusters, including Germany and Italy. An example of a large scale facilitated network was implemented in the United Kingdom (UK), through the National Industrial Symbiosis Programme (NISP), which received investment from the UK government in 2007-2013 and managed to achieve significant environmental and economic returns. The longest standing facilitated IS network is the Industrial Symbiosis Service in Northern Ireland, which has followed the NISP model. Outside the UK, there are examples of the facilitation structures in Finland, Denmark, Belgium, Italy and France, as well as in Central and Eastern Europe (Hungary, Romania, Poland, Slovenia). The latter might be relevant in regards to current political challenges in Europe and the creation of opportunities for those countries to reduce the eco-innovation gap in Europe. While these programmes exhibit large variation in terms of focus and geographical scope, the approach to facilitation has been based on adapting several elements of the UK NISP model. Planned initiatives are not uncommon but generally have a reduced in scale and take the form of eco-industrial parks and environmentally equipped industrial areas. Examples can be found scattered around Europe (UK, Germany, The Netherlands, Italy and others).

Assessment models for IS activity are rather fragmented and data not always available or consistent across initiatives. However, reported impact suggests that IS activity produced important environmental, economic and social benefits and contributed to increase the circularity of the manufacturing sector, by reducing dependence of primary raw materials and minimizing waste from the system. Thus it could contribute significantly to wider goals of resource security and climate action. However, results from the survey and interviews indicate that IS exchanges still face a number of obstacles in Europe, some of them related to risk and uncertainty and others with low commercial margins of IS projects and transaction costs. Better policies that foster collaborations, bring down transaction costs e.g. via indicators and encourage ambitious targets, are therefore pivotal to disseminate IS and promote more large-scale undertakings.

This research has highlighted three main areas of future research to stimulate IS in Europe: 1) the development of harmonized frameworks of assessment to quantitatively assess the impact of IS in the transition towards Circular Economy, and increase the ability to compare performance against different networks typologies and institutional frameworks; 2) The further understanding of the dynamics of IS emergence to foster the upscaling of IS initiatives and 3 ) the role of public policy and the key features of institutional frameworks conducive to IS.

\section{Acknowledgments}

The paper is based on the results of the EC project "Cooperation fostering industrial symbiosis: market potential, good practice and policy actions". This project has received funding from the European Commission, DG Growth under Framework Contract No 409/PP/2014/FC Lot 3. We would also like to acknowledge the insightful discussions with Anestis Filopoulos from DG Grow and the extremely helpful remarks of two anonymous reviewers. Any errors or omissions are solely the responsibility of the authors.

\section{References}

Baas, L. (2011). Planning and uncovering industrial symbiosis: Comparing the Rotterdam and Östergötland regions. Business Strategy and the Environment, 20(7), 428-440. https://doi.org/10.1002/bse.735

Boons, F., Spekkink, W., Mouzakitis, Y. (2011). The dynamics of industrial symbiosis: A proposal for a conceptual framework based upon a comprehensive literature review, Journal of Cleaner Production, 19: 905911.

Chertow, M. R. (2007). "Uncovering" Industrial Symbiosis. Journal of Industrial Ecology, 11(1). https://doi.org/10.1162/jiec.2007.1110 
Chertow, M., \& Ehrenfeld, J. (2012). Organizing Self-Organizing Systems: Toward a Theory of Industrial Symbiosis. Journal of Industrial Ecology, 16(1), 13-27.https://doi.org/10.1111/j.1530-9290.2011.00450.x Daddi, T., Nucci, B., Iraldo, F., Testa, F (2016). Enhancing the Adoption of Life Cycle Assessment by Small and Medium Enterprises Grouped in an Industrial Cluster: A Case Study of the Tanning Cluster in Tuscany (Italy), Journal of Industrial Ecology, 20 (5):1199-1211.

Daddi, T., Nucci, B., Iraldo, F. (2017). Using Life Cycle Assessment (LCA) to measure the environmental benefits of industrial symbiosis in an industrial cluster of SMEs, Journal of Cleaner Production, 147: 157-164.

Domenech, T. (2010). Social aspects of industrial symbiosis networks, PhD, available at:

http://discovery.ucl.ac.uk/762629/

Domenech, T., \& Davies, M. (2010). The role of Embeddedness in Industrial Symbiosis Networks: Phases in the Evolution of Industrial Symbiosis Networks. Business Strategy and the Environment, 20(5), 281-296. https://doi.org/10.1002/bse.695

Domenech, T., \& Davies, M. (2011). Structure and morphology of industrial symbiosis networks: The case of Kalundborg. Procedia - Social and Behavioral Sciences, 10, 79-89.https://doi.org/10.1016/j.sbspro.2011.01.011 Evans, S., Benedetti, M., \& Holgado Granados, M. Library of Industrial Symbiosis case studies and linked exchanges [Dataset]. https://doi.org/10.17863/CAM.12608

Invest Northern Ireland (2018). Industrial Symbiosis guide for businesses in Northern Ireland, available online at: https://secure.investni.com/static/library/invest-ni/documents/industrial-symbiosis-guide-for-businesses-innorthern-ireland.pdf

Jacobsen, N. B. (2006). Industrial symbiosis in Kalundborg, Denmark. Journal of Industrial Ecology, 10(1), 239255. https://doi.org/10.1162/108819806775545411

Jensen, P. D. (2016). The role of geospatial industrial diversity in the facilitation of regional industrial symbiosis. Resources, Conservation and Recycling, 107, 92-103. https://doi.org/10.1016/j.resconrec.2015.11.018

Jensen, P. D., Basson, L., Hellawell, E. E., Bailey, M. R., \& Leach, M. (2011). Quantifying "geographic proximity": Experiences from the United Kingdom's National Industrial Symbiosis Programme. Resources, Conservation and Recycling, 55(7), 703-712. https://doi.org/10.1016/j.resconrec.2011.02.003

Jiao, W., Boons, F., Teisman, G., Li, G. (2018). Durable policy facilitation of Sustainable Industrial Parks in China: A perspective of co-evolution of policy processes, Journal of Cleaner Production, 192: 179-190.

Lehtoranta, S., Nissinen, A., Mattila, T., \& Melanen, M. (2011). Industrial symbiosis and the policy instruments of sustainable consumption and production. Journal of Cleaner Production, 19(16), 1865-1875. https://doi.org/10.1016/j.jclepro.2011.04.002

Lieder, M., Rashid, A. (2016). Towards circular economy implementation: a comprehensive review in context of manufacturing industry, Journal of Cleaner Production, 115 (1): 36-51.

Lombardi, D. R., \& Laybourn, P. (2012). Redefining Industrial Symbiosis: Crossing Academic-Practitioner Boundaries. Journal of Industrial Ecology, 16(1), 28-37. https://doi.org/10.1111/j.1530-9290.2011.00444.x

Martin, M., Svensson, N., Fonseca, J., Eklund, M. (2014). Quantifying environmental performance of integrated bioethanol and biogas production. Renewable Energy, 61, 109-116. https://www.sciencedirect.com/science/article/pii/S0960148112006581

Matthew, J., Tan, H. (2011). Progress Toward a Circular Economy in China. The Drivers (and Inhibitors) of EcoIndustrial Initiative, Journal of Industrial Ecology, 15 (3): 435-457.

NISP (2013). Opportunities through Industrial Symbiosis: UK NISP and Global Experience, available online at: http://www.endustriyelsimbiyoz.org/wp-content/uploads/2013/02/industrial-symbiosis_uk-nisp-and-globalexperience_31.01.2013.pdf

Nordregio, Johnsen, I. H. G., Berlina, A., Lindberg, G., Mikkola, N., Olsen, L. S., \& Teräs, J. (2015). The potential of industrial symbiosis as a key driver of green growth in Nordic regions. Retrieved from http://www.nordregio.se/en/Publications/Publications-2015/Thepotential-of-industrial-symbiosis-as-a-keydriver-of-green-growth-in-Nordic-regions/

Paquin, R. L., \& Howard-Grenville, J. (2009). Facilitating Regional Industrial Symbiosis: Network Growth in the UK's National Industrial Symbiosis Programme. The Social Embeddedness of Industrial Ecology, 103-127. https://doi.org/10.1111/j.1530-9290.2011.00437.x

Paquin, R. L., \& Howard-Grenville, J. (2011). The Evolution of Facilitated Industrial Symbiosis. Journal of Industrial Ecology, 16(1), 83-93. https://doi.org/10.1111/j.1530-9290.2011.00437.x

Posch, A. (2010). Industrial Recycling Networks as Starting Points for Broader Sustainability-Oriented Cooperation? Journal of Industrial Ecology, 14(2), 242-257. https://doi.org/10.1111/j.1530-9290.2010.00231.x Sofies (2014). International survey on eco-innovation parks, available online at: https://www.cittametropolitana.bo.it/imprese/Engine/...php/f/.../D1.D2_ppt_Jaquet.pdf

Simboli, A, Taddeo, R., Morgante, A. (2014). Analysing the development of Industrial Symbiosis in a motorcycle local industrial network: the role of contextual factors, Journal of Cleaner Production, 66:372-383.

Su, B., Heshmati, A. Geng, Y., Yu, X. (2013). A review of the circular economy in China: moving from rethoric to implementation, Journal of Cleaner Production, 42: 215-227, available online at: 
https://www.sciencedirect.com/science/article/pii/S0959652612006117.

Sun, L., Li, H., Dong, L., Fang, K, Ren, J, Geng, Y., Fujii, M., Zhang, W., Zhang, N., Liu, Z. (2017). Eco-benefits assessment on urban industrial symbiosis based on material flows analysis and emergy evaluation approach: A case of Liuzhou city, China, Resources, Conservation and Recycling, 119:78-88.

Taddeo, R., Simboli, A., Morgante, A. (2012). Implementing eco-industrial parks in existing clusters. Findings from a historical Italian chemical site, Journal of Cleaner Production, 33:22-29.

Taddeo, R., Simboli, A., Morgante, A., Erkman, S. (2017). The Development of Industrial Symbiosis in Existing Contexts. Experiences From Three Italian Clusters, Journal of Cleaner Production, 139: 53-67.

Yuan, Z. and Shi, L. (2009). Improving enterprise competitive advantage with industrial symbiosis: case study of a smeltery in China, Journal of Cleaner Production, 17 (14): 1295-1302.

Wen, Z. and Meng, X. (2015). Quantitative assessment of industrial symbiosis for the promotion of circular economy: a case study of the printed circuit boards industry in China's Suzhou New District, Journal of Cleaner Production, 90: 211-219.

Zander, S., Trang, S., Kolbe, L. (2016). Drivers of network governance: a multitheoretic perspective with insights from case studies in the German wood industry, Journal of Cleaner Production, 110: 109-120.

\section{Case studies’ references (Appendix I)}

Albertsson, A., \& Jónsson, J. (2010). The Svartsengi Resource Park. 10World Geothermal Congress 2010, (April), 1-2.

Allard, V., Broberg, N., Danielsson, E., Elmtoft, E., Lindström, G., Nelénius, M., ... Österqvist, J. (2016). Industry Park of Sweden. Retrieved from http://www.industriellekologi.se/documents/IPOS.pdf

Angren, J., Arnoldsson, J., Arvidsson, J., Baumgarten, S., Dijkstra, S., Högström, C., ... Willman, A. (2012). Exploring the Industrial Symbiosis in Lidköping, Sweden. Retrieved from http://www.industriellekologi.se/documents/Lidkoping.pdf

A-R-D Innovation in Green. (n.d.). Bio-raffinerie Recherces et Innovations. Retrieved from http://www.a-r-d.fr/ARD-filiales-et-partenaires-Bio-raffinerie-Recherches-et-InnovationsBRI-68.html

Baas, L. (2008). Industrial symbiosis in the Rotterdam Harbour and Industry Complex: Reflections on the interconnection of the techno-sphere with the social system. Business Strategy and the Environment, 17(5), 330-340. http://doi.org/10.1002/bse.624

Baas, L. W. (2007). Industrial Ecology as Regional Corporate Sustainability System. Sustainable Social and Ecosystem Stewardship.

Baas, L. W., \& Huisingh, D. (2008). The synergistic role of embeddedness and capabilities in industrial symbiosis: illustration based upon 12 years of experiences in the Rotterdam Harbour and Industry Complex. Progress in Industrial Ecology, An International Journal, 5(5/6), 399. http://doi.org/10.1504/PIE.2008.023408

Benedetti, M. (2017). The Portuguese experience of the Relvão Eco Industrial Park: influencing contextual factors to overcome legislative barriers. Retrieved from https://maestri-spire.eu/case-17-industrial-park-planned-national-level-portugueseexperience-relvao-eco-industrial-park/

Biopark Terneuzen. (n.d.). Biopark Terneuzen. Retrieved from http://www.bioparkterneuzen.com/en/biopark.htm\%0A

Cecelja, F., Raafat, T., Trokanas, N., Innes, S., Smith, M., Yang, A., ... Kokossis, A. (2015). e-Symbiosis: Technology-enabled support for Industrial Symbiosis targeting Small and Medium Enterprises and innovation. Journal of Cleaner Production, 98, 336-352. http://doi.org/10.1016/j.jclepro.2014.08.051

Chauvet, J.-M. (n.d.). La bioraffinerie de Bazancourt-Pomacle: un modèle d' intégration au cœur du pôle IAR.

Chauvet, J.-M. (n.d.). The Biorefinery of Pomacle Bazancourt and the BRI platform.

Retrieved from www.a-r-d.fr 
CONSER. (2018). What is the 1st Industrial Macrolotto of Prato (CHE COS'È IL $1^{\circ}$ MACROLOTTO INDUSTRIALE DI PRATO). in italian. Retrieved from

$\mathrm{http}$ ://www.conseronline.it/index.php?option $=$ com_content\&view $=$ article $\& \mathrm{id}=25 \& \mathrm{Itemid}=18$ Consorzio Industriale. (n.d.). Retrieved from http://www.consorzioindustriale.com Cutaia, L., Barberio, G., Luciano, A., Manusco, E., Sbaffoni, S., La Monica, M., \& Scagliarino, C. (2014). A systematic Methodology for Industrial Symbiosis Approach Development at a Regional Scale, (Eu 2008), 1-7.

Cutaia, L., Luciano, A., Barberio, G., Sbaffoni, S., Mancuso, E., Scagliarino, C., \& La Monica, M. (2015). The experience of the first industrial symbiosis platform in Italy. Environmental Engineering and Management Journal, 14(7), 1521-1533.

Cutaia, L., Mancuso, E., Sbaffoni, S., Luciano, A., \& Barberio, G. (2014). First results of the implementation of the Industrial Symbiosis Platform in Italy, 1-8.

Daddi, T., Nucci, B., Iraldo, F. (2017). Using Life Cycle Assessment (LCA) to measure the environmental benefits of industrial symbiosis in an industrial cluster of SMEs, Journal of Cleaner Production, 147: 157-164.

Daddi, T., Nucci, B., Iraldo, F., Testa, F (2016). Enhancing the Adoption of Life Cycle Assessment by Small and Medium Enterprises Grouped in an Industrial Cluster: A Case Study of the Tanning Cluster in Tuscany (Italy), Journal of Industrial Ecology, 20 (5):11991211.

den Boer, E., Williams, I. D., Curran, T., \& Kopacek, B. (2014). Briefing: Demonstrating the circular resource economy - the Zerowin approach. Proceedings of the Institution of Civil Engineers - Waste and Resource Management, 167(WR3).

http://doi.org/10.1680/warm.14.00005

Domenech, T. (2010). Social Aspects of Industrial Symbiosis Networks, PhD Thesis, University College London.

Domenech, T., \& Davies, M. (2011). Structure and morphology of industrial symbiosis networks: The case of Kalundborg. Procedia - Social and Behavioral Sciences, 10, 79-89. http://doi.org/10.1016/j.sbspro.2011.01.011

Ecodyfi. (n.d.). Ecodyfi. Retrieved from http://www.ecodyfi.org.uk/

ECSPP. (n.d.). Chemical Parks of Europe. Port of Le Havre. Retrieved from

https://chemicalparks.eu/parks/port-of-le-havre

Eklund, \& Gustafsson. (2015). Ten challenges for a sustainable Norrköping (translated from Swedish. in Johnsen et al. 2015).

eSymbiosis. (2014). eSYMBIOSIS Deveopment of knowledge-based web services to promote and advance Industrial Symbiosis in Europe. Layman's Report.

European Commission. (2011). LIFE08 ENV / H / 000291 Mid-term Report ISIM-TCCIndustrial Symbiosis an Innovative Method in Tackling Climate Change Data Project. European Commission. (2012). European Resource Efficiency Platform (EREP). Retrieved from http://ec.europa.eu/environment/resource_efficiency/re_platform/index_en.htm European Commission. (2012). Final Report ISIM-TCC-Industrial Symbiosis an Innovative Method in Tackling Climate Change, 1-57. Retrieved from

$\mathrm{http} / /$ ec.europa.eu/environment/life/project/Projects/index.cfm?fuseaction=home.showFile\& rep=file\&fil=LIFE08_ENV_H_000291_FTR.pdf

European Commission. (2014). eSymbiosis: Development of knowledge-based web services to promote and advance Industrial Symbiosis in Europe: AFTER-LIFE Communication Plan. Retrieved from www.esymbiosis.gr European Commission. (2015). A framework for Member States to support business in improving its resource efficiency. Retrieved from http://ec.europa.eu/environment/enveco/resource_efficiency/pdf/business/RE_in_Business_ M1_IndustrialSymbiosis.pdf 
European Commission. (2015). Construction and Demolition Waste management in Hungary, (September).

European Commission. (2015). Fostering Industrial Symbiosis for a Sustainable Resource Intensive Industry Across the Extended Construction Value Chain. Retrieved from https://cordis.europa.eu/project/ren/196821_en.html European Commission. (n.d.). ECOREG - Application of industrial ecosystems principles to regional development - ECOREG LIFE07 ENV/RO/000690. Retrieved from

http://ec.europa.eu/environment/life/project/Projects/index.cfm?fuseaction=home.showFile\& rep=file\&fil=LIFE07_ENV_RO_000690_AfterLIFE.pdf

European Commission. (n.d.). ISIM-TCC - Industrial Symbiosis as an Innovative Method in Tackling Climate Change. Retrieved from

http://ec.europa.eu/environment/life/project/Projects/index.cfm?fuseaction=search.dspPage\& n_proj_id $=3398 \&$ docType $=$ pdf

FebelAuto. (2011). Collecting results end-of-life vehicles in Belgium Recycling-reuse-

recovery results for Belgium - evolution 2006-2011, 2008-2012.

Finnish Idustrial Symbiosis System. (n.d.). Retrieved from http://www.industrialsymbiosis.fi/ Flanders. (n.d.). Flanders' recycling ecosystem. Retrieved from

https://www.flandersinvestmentandtrade.com/invest/en/sectors/sustainable-

materials/recycling-industry/recycling-ecosystem

formule-verte.com. (n.d.). Bazancourt-Pomacle, une des 17 grandes plateformes chimiques

du territoire. Retrieved from http://formule-verte.com/bazancourt-pomacle-une-des-17-

grandes-plateformes-chimiques-du-territoire/

French Ministry of Agriculture and Food. (2016). Transformer la Bioraffinerie de Bazancourt

Pomacle. Retrieved from http://agriculture.gouv.fr/transformer-la-bioraffinerie-de-

bazancourt-pomacle\%0A

GEKON. (2011). Suðurnes Resource Park, (December).

Ghent Bio-Economy Valley. (n.d.). Biopark Terneuzen. Retrieved from

http://www.gbev.org/en/members/biopark-terneuzen

Grand Reims Communauté Urbaine. (n.d.). La bioraffinerie de Bazancourt - Pomacle.

Retrieved from http://www.grandreims.fr/les-competences/enseignement-superieur-

recherche-innovation/recherche-et-innovation/la-bioraffinerie-de-bazancourt-pomacle-

7912.html

Green Tech Cluster. (n.d.). The Green Tech Valley. Retrieved from

https://www.greentech.at/en/green-tech-valley-2/

HAROPA. (2014). Bilan Des Emissions De Gaz a Effet De Serre (Ges). Retrieved from

http:/www.haropaports.com/sites/haropa/files/u21/synthese_reglementaire_v2014_bilan_ges gpmh.pdf

Heino, J., \& Koskenkari, T. (2004). Industrial ecology and the metallurgy industry. The Harjavalta industrial ecosystem. Proceedings of the Waste Minimization and Resource Use Optimization, (Erkman), 143-151. Retrieved from

http://www.oulu.fi/resopt/wasmin/heino2.pdf

Horvath, C. (n.d.). The ZeroWIN Production Model. A new kind of production model.

Retrieved from www.zerowin.eu

IAR. (2012). Le complexe agro-industriel des Sohettes.

Igeam. (2006). $1^{\circ}$ Macrolotto Industriale Di Prato Sustainability Analysis. Retrieved from http://www.life-siam.bologna.enea.it/files/definitivi/task4/doc_finali/asfinali/as_PO_def.pdf Industriellekologi. (n.d.). Enköping Industrial Symbiosis Network. Retrieved from

http://www.industriellekologi.se/symbiosis/enkoping.html

Industriellekologi. (n.d.). Industrial Symbiosis in Avesta. Retrieved from

http://www.industriellekologi.se/symbiosis/avesta.html 
Industriellekologi. (n.d.). Industrial Symbiosis in Stenungsund. Retrieved from

http://www.industriellekologi.se/symbiosis/stenungsund.html

Industriellekologi. (n.d.). Industry Park of Sweden. Retrieved from

http://www.industriellekologi.se/symbiosis/ipos.html

Industriellekologi. (n.d.). Lidköping Industrial Symbiosis Network. Retrieved from

http://www.industriellekologi.se/symbiosis/lidkoping.html

Jacobsen, N. B. (2006). Industrial symbiosis in Kalundborg, Denmark. Journal of Industrial Ecology, 10(1), 239-255. http://doi.org/10.1162/108819806775545411

Jurado, L. (2012). 85a Jornada Tècnica : La gestió de residus Funcionament de la Borsa de Subproductes de Catalunya.

Knapsack Park http://www.chemiepark-knapsack.de Infraserv Knapsack http://www.infraserv-knapsack.de/

Mancuso, E., \& Luciano, A. (2014). Experiences of Industrial Symbiosis in Italy. In ENEA at Ecomondo.

Markatos, N. (n.d.). eSYMBIOSIS - Development of knowledge-based web services to promote and advance Industrial Symbiosis in Europe. Retrieved from

http://ec.europa.eu/environment/life/project/Projects/index.cfm?fuseaction=search.dspPage\& n_proj_id $=3680 \&$ doc Type $=$ pdf

Mercado Organizado de Residuos. (n.d.). Mercado Organizado de Residuos. Retrieved from http://www.moronline.pt/UK/index.asp

Mikkola, N., \& Randall, L. (2016). Growth in Nordic Regions.

Mikkola, N., \& Randall, L. (2016). Growth in Nordic Regions.

Mikkola, N., \& Randall, L. (2016). Growth in Nordic Regions.

Monceau-Fontaines ASBL. (2014). Activity Report 2014 (Rapport d'activités 2014). in

french. Retrieved from https://www.monceau-fontaines.be/wp-

content/uploads/2017/07/Rapport-dactivités-2014.pdf

NISP. (2012). Industrial Symbiosis as an Innovative Method in Tackling Climate change.

Nordregio, Johnsen, I. H. G., Berlina, A., Lindberg, G., Mikkola, N., Olsen, L. S., \& Teräs, J. (2015). The potential of industrial symbiosis as a key driver of green growth in Nordic regions. Retrieved from http://www.nordregio.se/en/Publications/Publications-2015/Thepotential-of-industrial-symbiosis-as-a-key-driver-of-green-growth-in-Nordic-regions/ Norilsk Nickel. (2011). Corporate Social Responsibility Report MMC Norilsk Nickel. O'Connor, C., Hestin, M., \& Kuehr, R. (2010). ZeroWin Policy Synthesis Report. Retrieved from http://www.4980.timewarp.at/sat/ZeroWIN/pdf_secure/D.8.1 Policy Synthesis Report.pdf

Oliva, J. (n.d.). By-Product Recycling Network Trust is an important determinant factor of knowledge transfer in company recycling networks.

Orée Entreprises territoires et environement. (n.d.). Industrial and territorial ecology.

Retrieved from http://www.oree.org/en/sustainable-management-of-industrial-parks-andindustrial-ecology.html

Öresundskraft årsredovisning 2013 (Öresundskraft annual report 2013). (2013). Retrieved from oresundskraft.se

OVAM. (n.d.). Ecoclusters: bevordering van industriële symbiose. Retrieved from http://www.ovam.be/ecoclusters-bevordering-van-industriele-symbiose Parc de l'Alba. (n.d.). ¿QUÉ ES EL PARQUE? (What is the park). in spanish. Retrieved from https://www.parcdelalba.cat/ES/2006/menu/presentacion.html\#2134 PNSI. (n.d.). Programme National de Synergies Inter-Entreprises. Retrieved from www.pnsi.fr 
Posch, A. (2010). Industrial Recycling Networks as Starting Points for Broader

Sustainability-Oriented Cooperation? Journal of Industrial Ecology, 14(2), 242-257.

http://doi.org/10.1111/j.1530-9290.2010.00231.x

Recupel. (2015). 2015 Annual Report BASTION OF In 2015, Recupel was able to motivate every Belgian to bring in an average $10 \mathrm{~kg}$ of electrical and electronic waste.

RecyTyre. (2015). Annual Report 2015.

ResiduoRecurso. (n.d.). WasteResource raw material and by-product exchange. Retrieved from http://www.residuorecurso.com/en/inici

Rethink. (n.d.). Rethink - Sustainable Solutions. Retrieved from https://www.rethink.srl/

Sanchez, B. J., Munoz de la Torre, D. H., Cepria Pamplona, J. J., \& Bustamante, E. G. (n.d.).

FISSAC: Fostering Industrial Symbiosis for a Sustainable Resource Intensive Industry

Across the Extended Construction Value Chain.

Saraev, A., \& Obersteiner, G. (2014). Assessing Sustainability in Industrial Networks. Based on the Experience From Zerowin Project.

Schwarz, E. J., \& Steininger, K. W. (1997). Implementing nature's lesson: the industrial recycling network enhancing regional development. Journal of Cleaner Production Cleaner Production, 5(12), 47-56. http://doi.org/10.1016/S0959-6526(97)00009-7

Scottish Government. (n.d.). Industrial Symbiosis Project 2007-08. Retrieved from https://www.gov.scot/Topics/Environment/SustainableDevelopment/funding/Aggregatesproj ects2007-08/industrialsymbiosis07-08

Scottish Government. (n.d.). Scottish Industrial Symbiosis Programme. Retrieved from https://www.gov.scot/Topics/Environment/SustainableDevelopment/funding/Aggregatesproj ects2002-07/IS

Sööder, F., Nilsson, M., Olevik, J., Forsberg, J., Jacobsson, A., Holm, L., ... Ekman, O. (2014). Industrial Symbiosis in Enköping.

Suurteollisuuspuisto, H. (2010). Historian vuosikymmenet.

Tarantini, A. M., Paolo, A. Di, Dominici, A., Peruzzi, A., Isola, M. D., Cucchi, E. E., ... Cutaia, L. (n.d.). Guidelines for the Settlement and the Management of the Sustainable Industrial Areas. The experience of the LIFE SIAM Project.

Weterings RAPM. (2000). Agroproductieparken - Perspectieven en Dilemma's. Rapportage in Opdracht van Innovatie Netwerk Groene Ruimte en Agrocluster. TNO: Apeldoorn. Williams, I. (2014). ZeroWIN Practical Demonstrators: Demolition and New Buildings in Germany, Portugal and the United Kingdom. Retrieved from www.zerowin.eu Williams, I., \& Curran, T. (2010). Literature Review “Approaches To Zero Waste.” Williams, I., Curran, T., \& Ongondo, F. (2011). Report on the Zerowin Vision Conference. ZIP Padova. (n.d.). ZIP Padova. Retrieved from https://www.zip.padova.it/index.php 
Table 3: Mapping of IS networks in Europe (Source: authors' elaborated) 


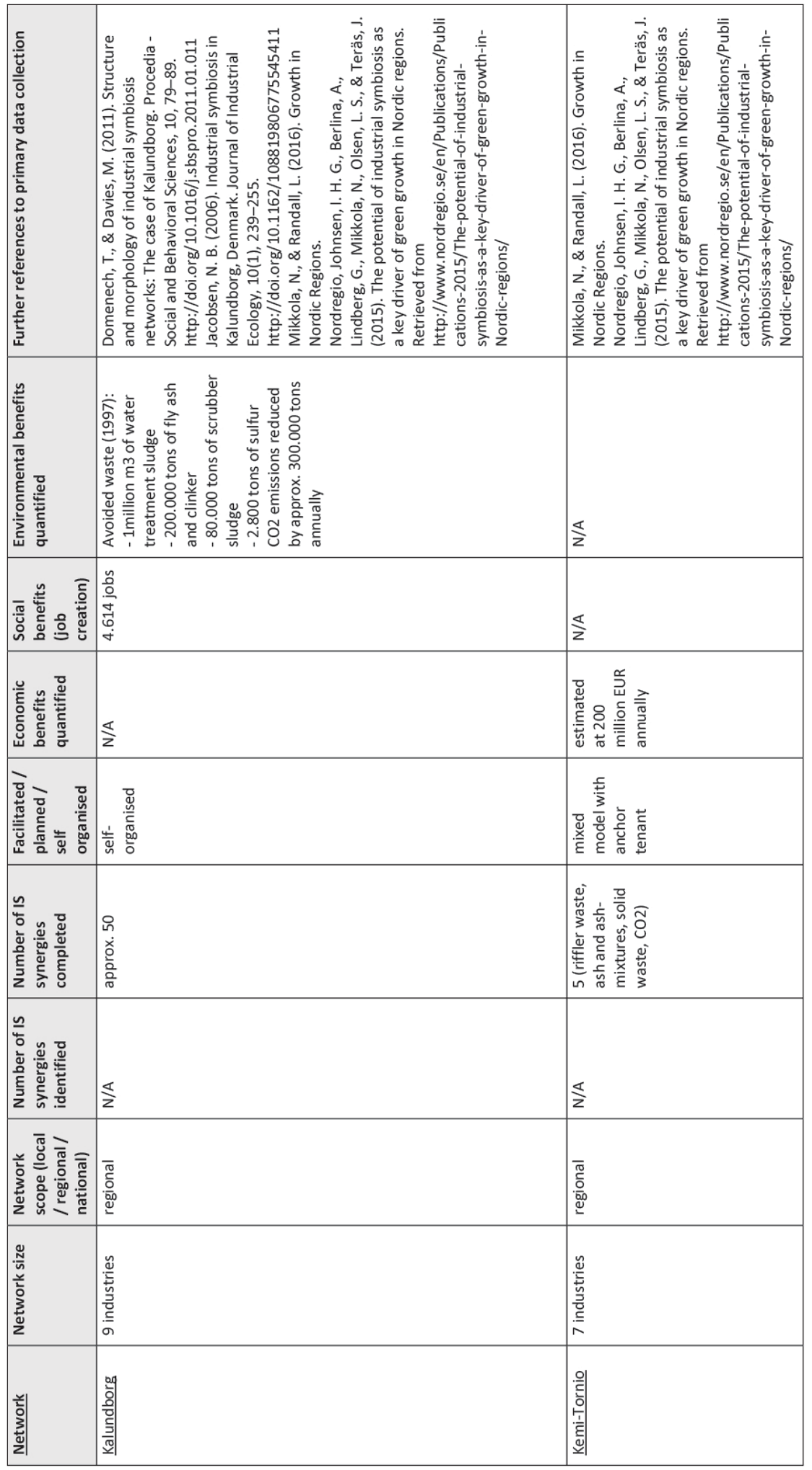




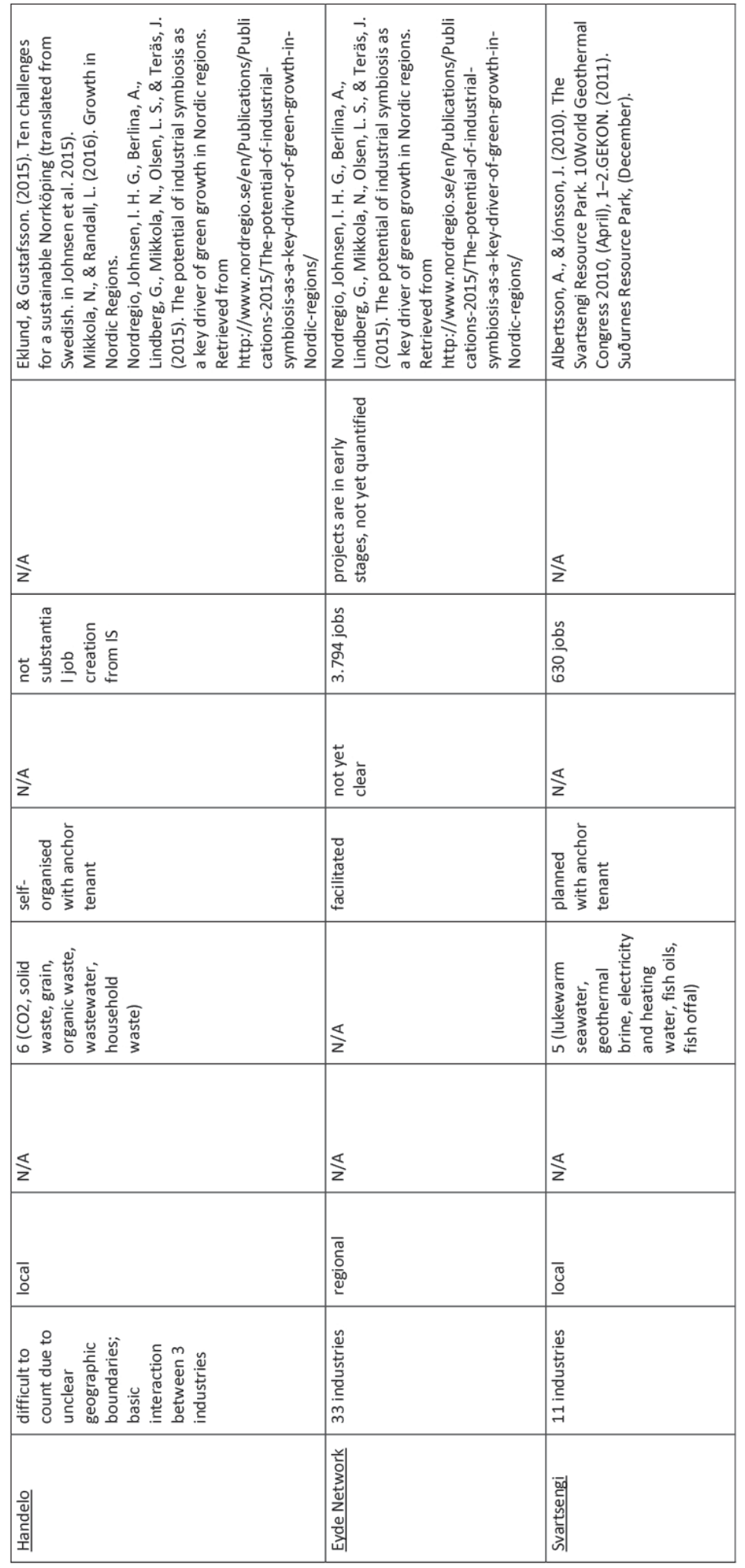




\begin{tabular}{|c|c|c|}
\hline 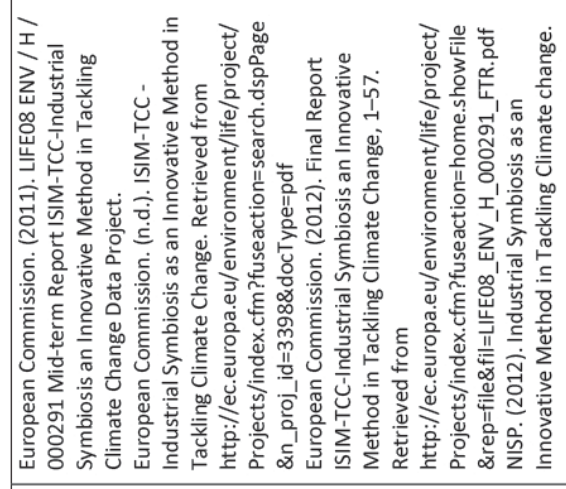 & 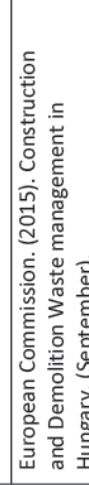 & 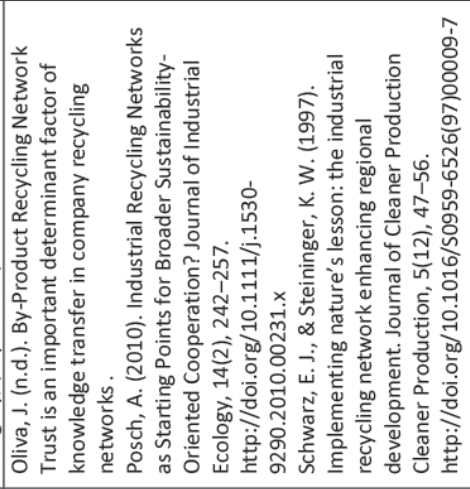 \\
\hline 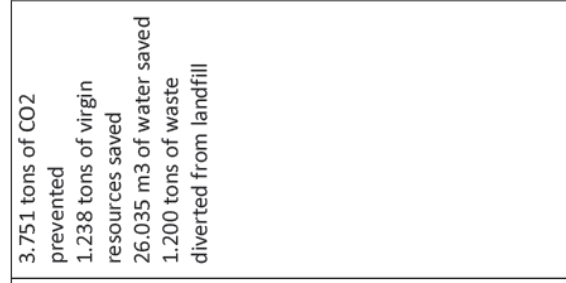 & $\frac{\pi}{z}$ & 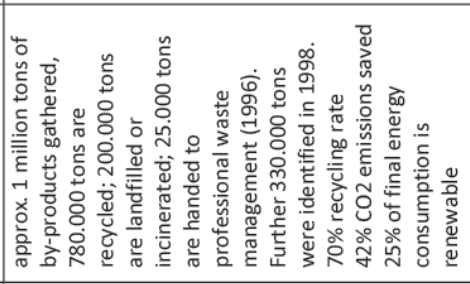 \\
\hline$\frac{\mathbb{s}}{z}$ & $\frac{\pi}{z}$ & 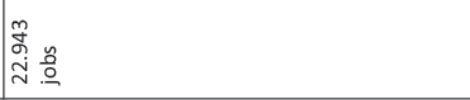 \\
\hline$\frac{\varangle}{z}$ & $\frac{\mathbb{s}}{z}$ & \\
\hline 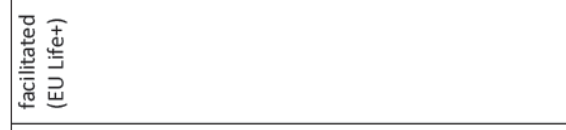 & 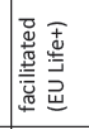 & 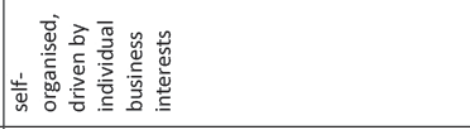 \\
\hline$\frac{\mathbb{s}}{z}$ & $\frac{\varangle}{z}$ & 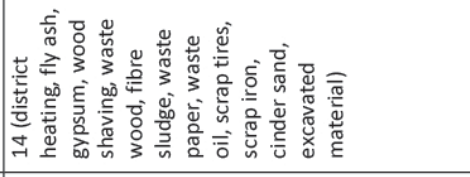 \\
\hline 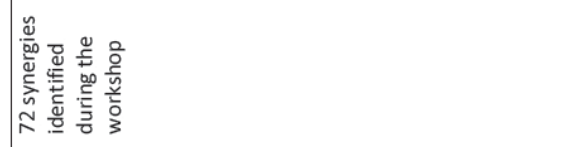 & $\frac{s}{z}$ & $\frac{\pi}{z}$ \\
\hline 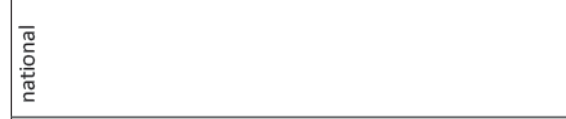 & 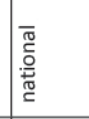 & 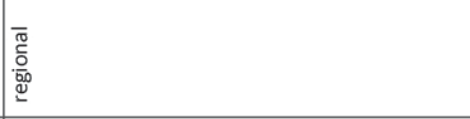 \\
\hline 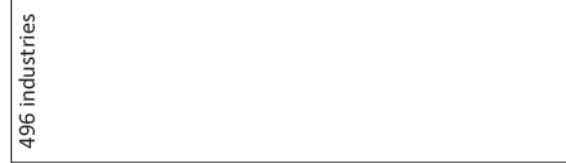 & $\mathbb{z}$ & 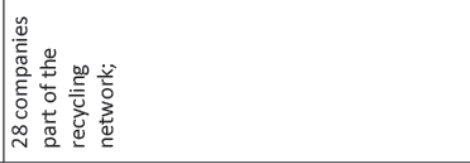 \\
\hline 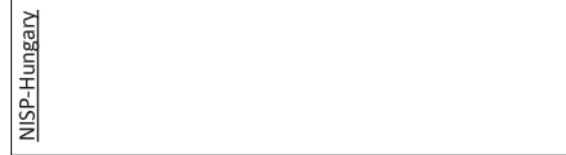 & $\mid$ & 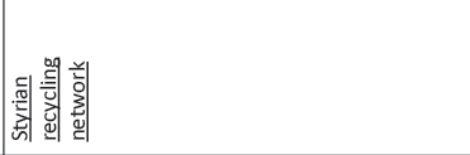 \\
\hline
\end{tabular}




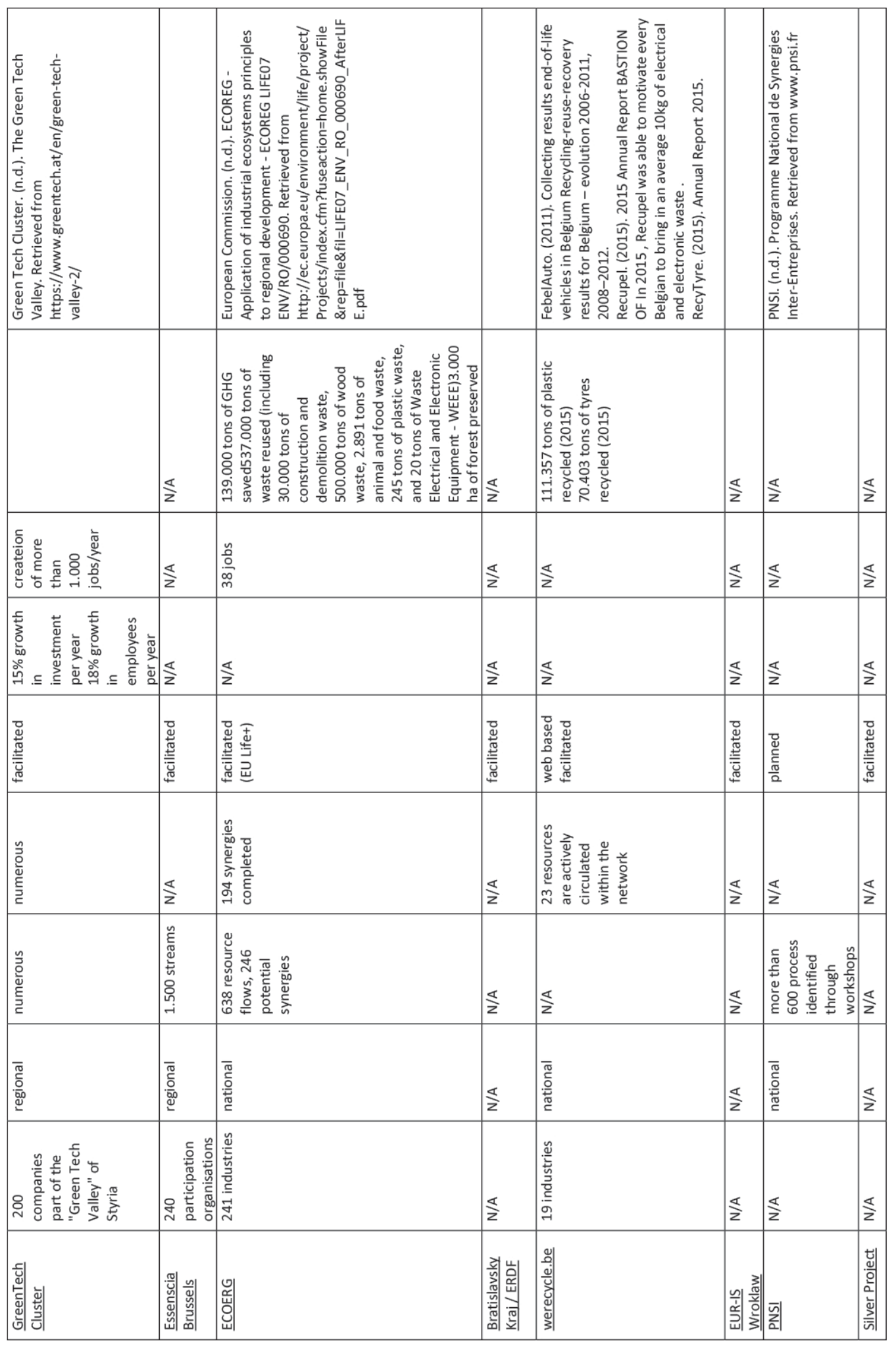




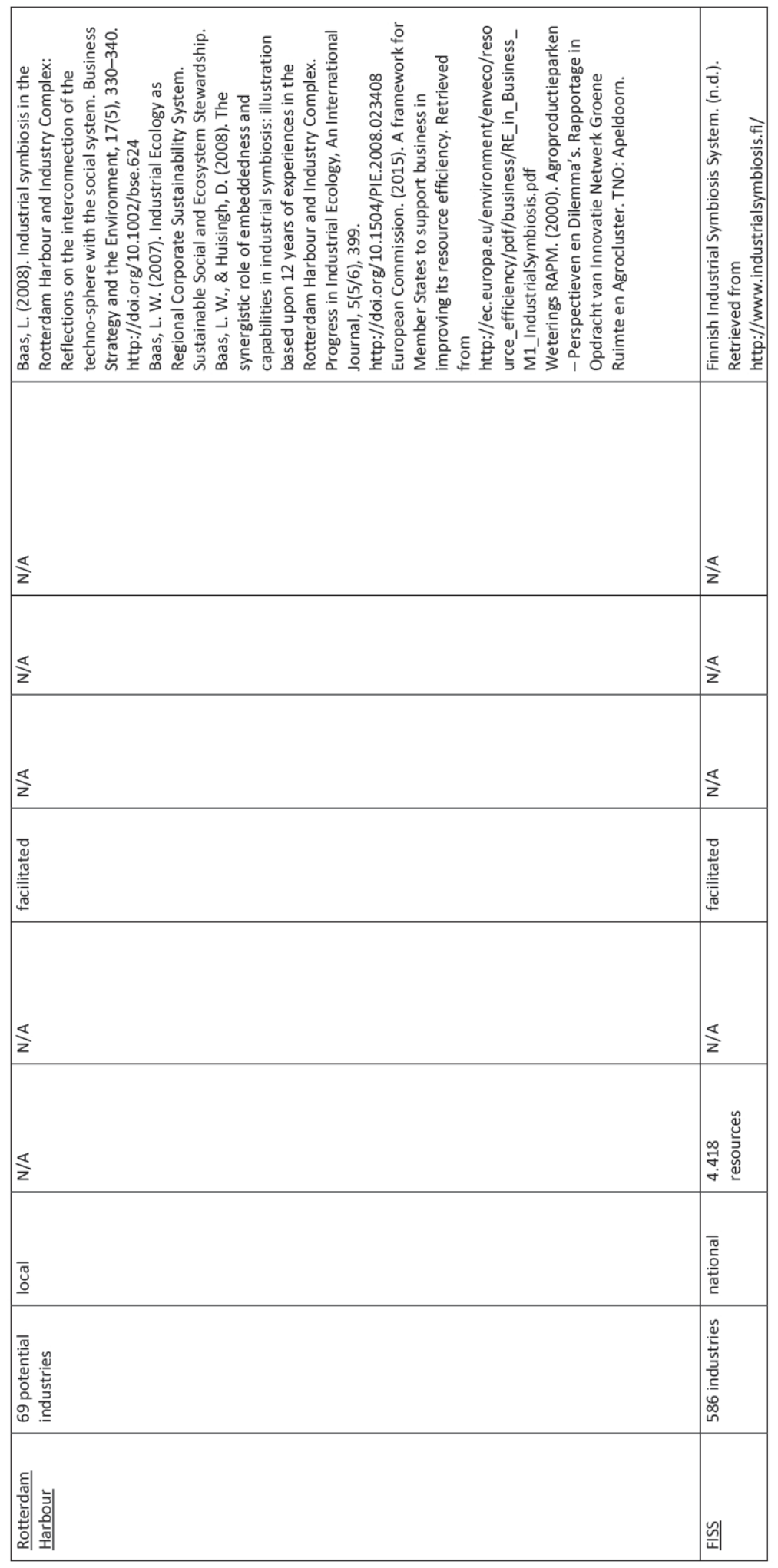




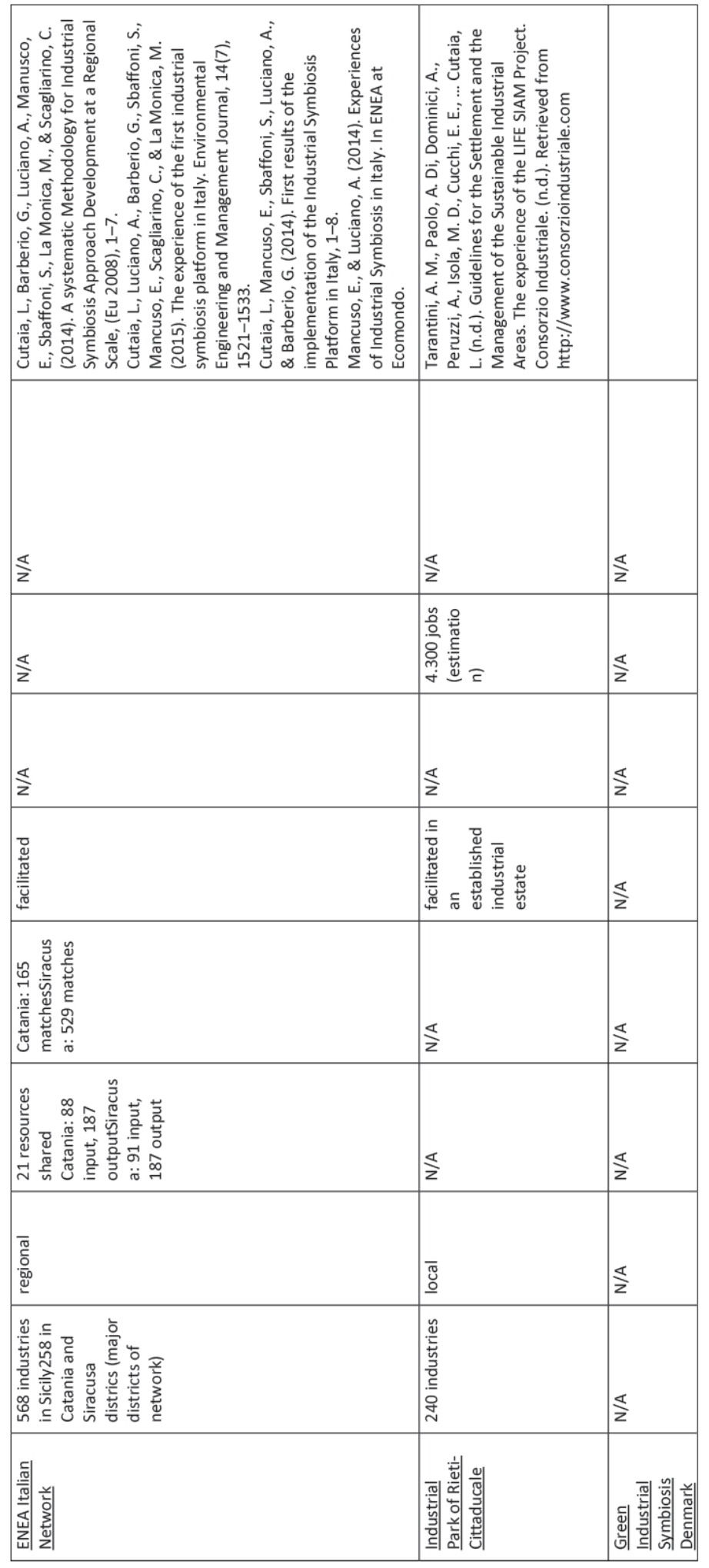




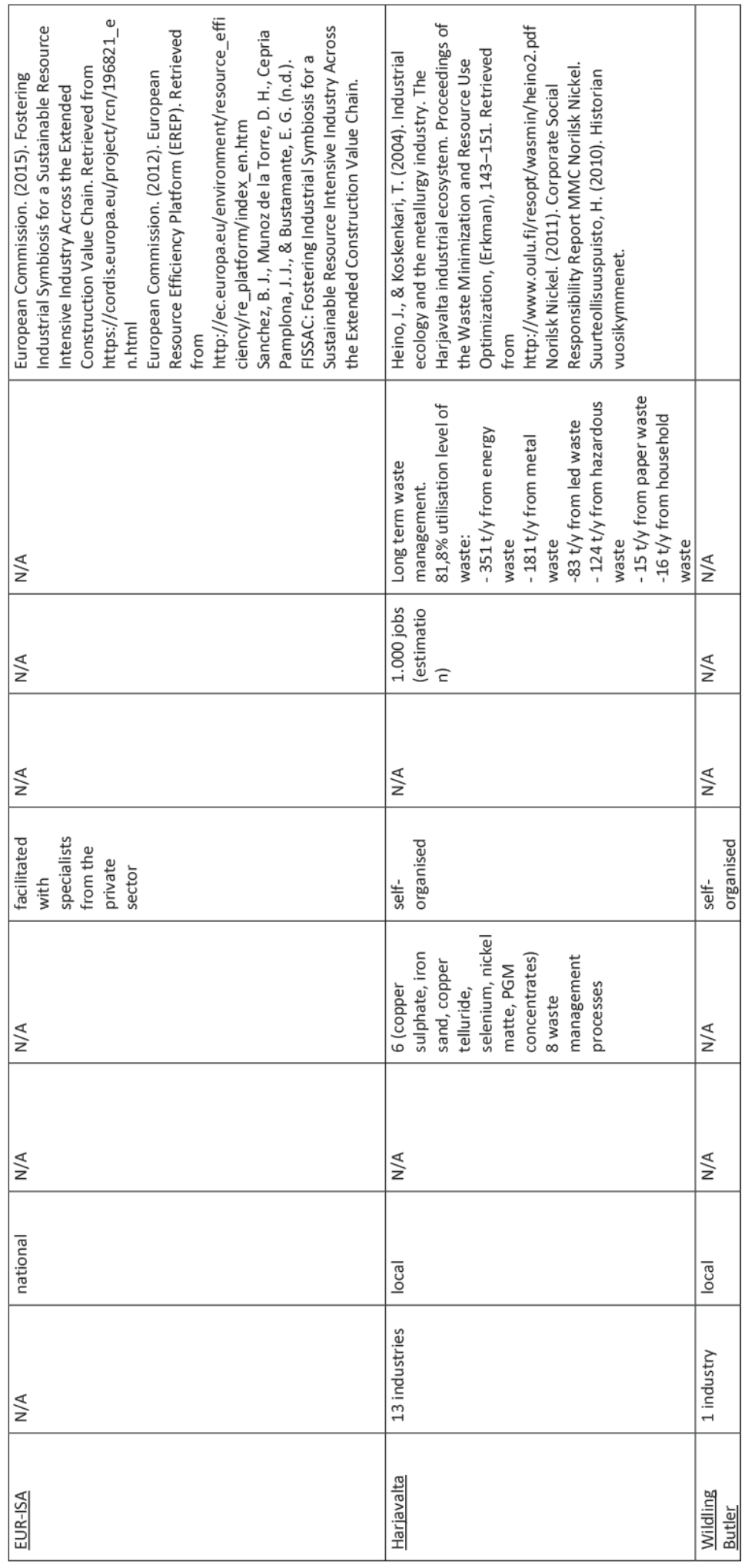




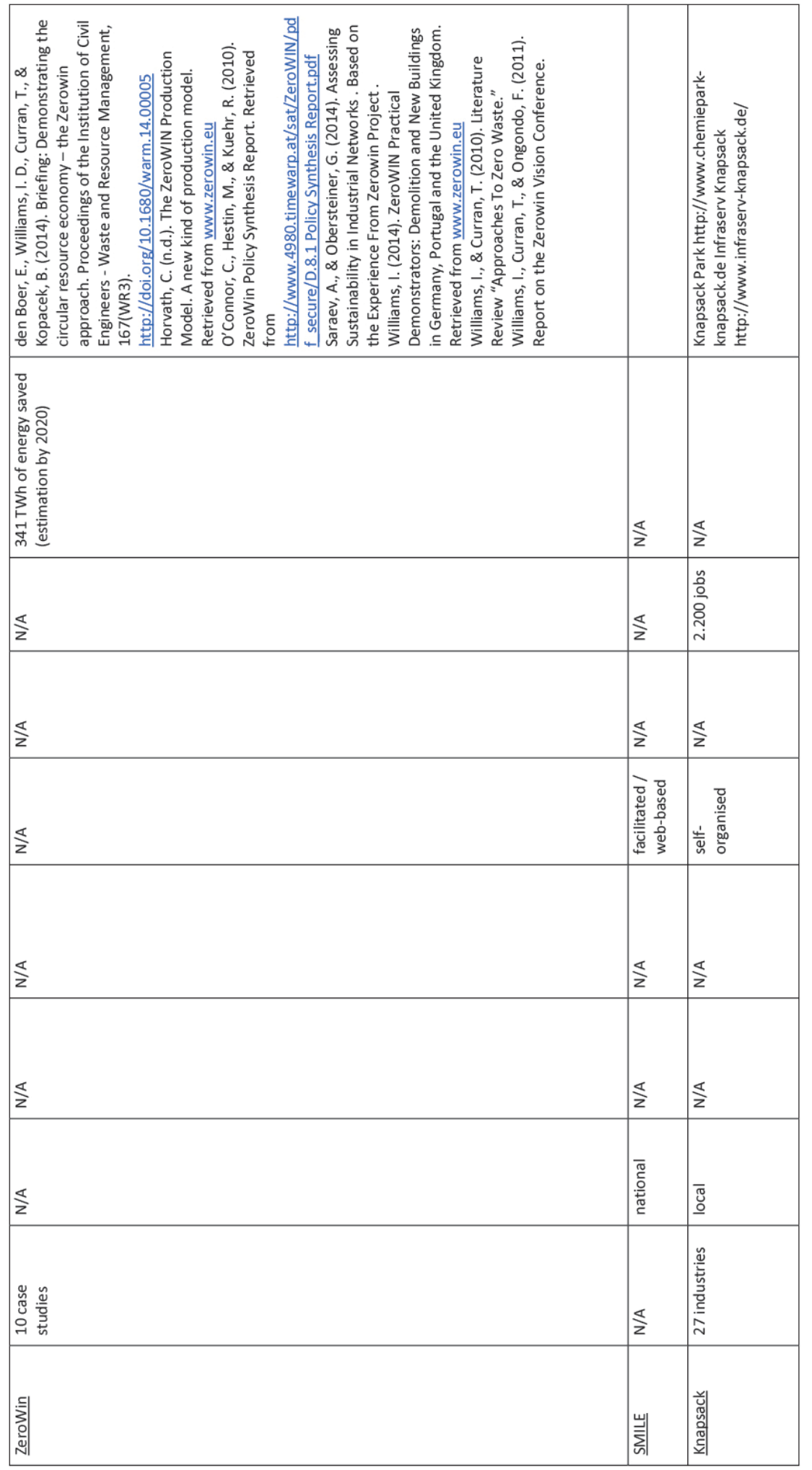




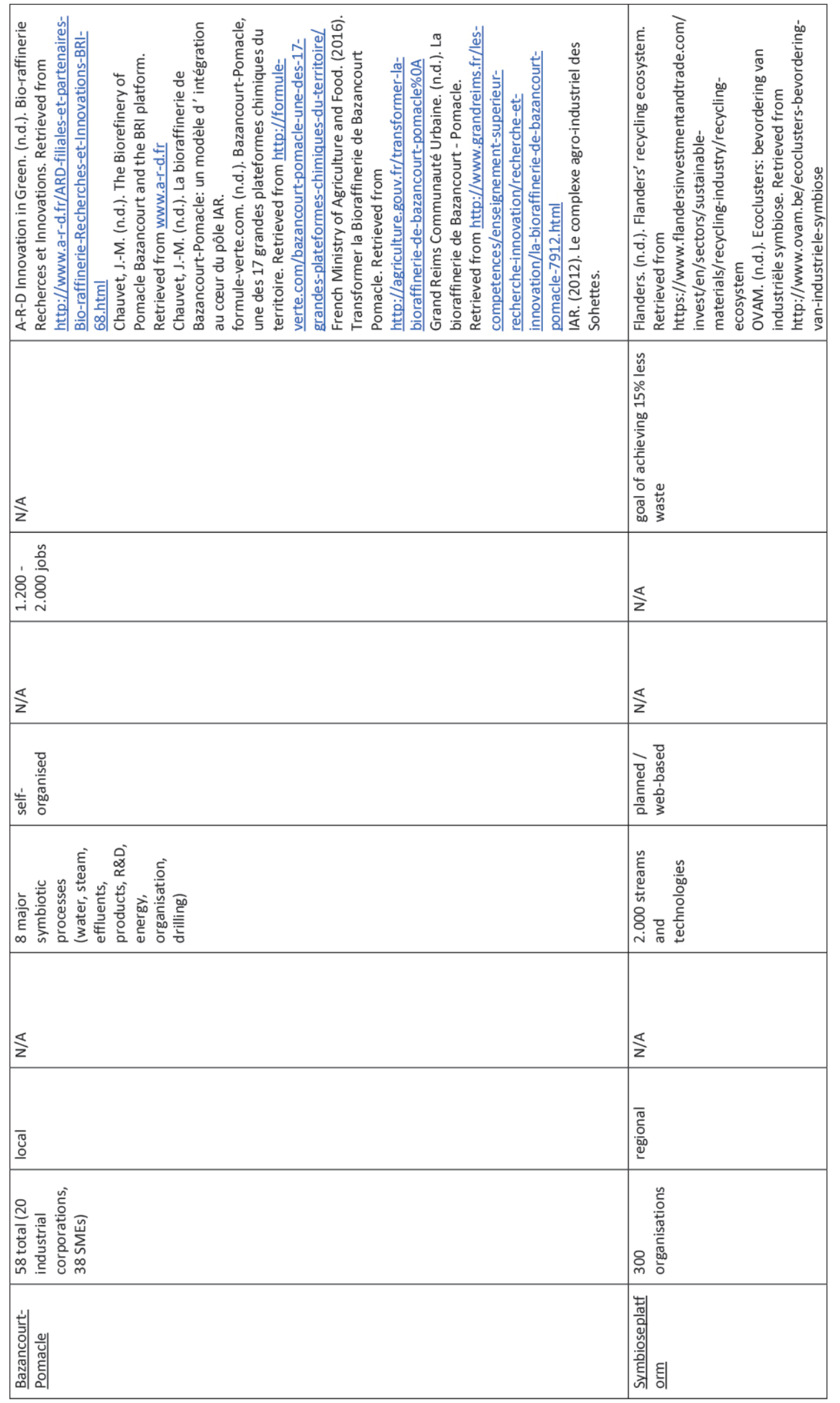




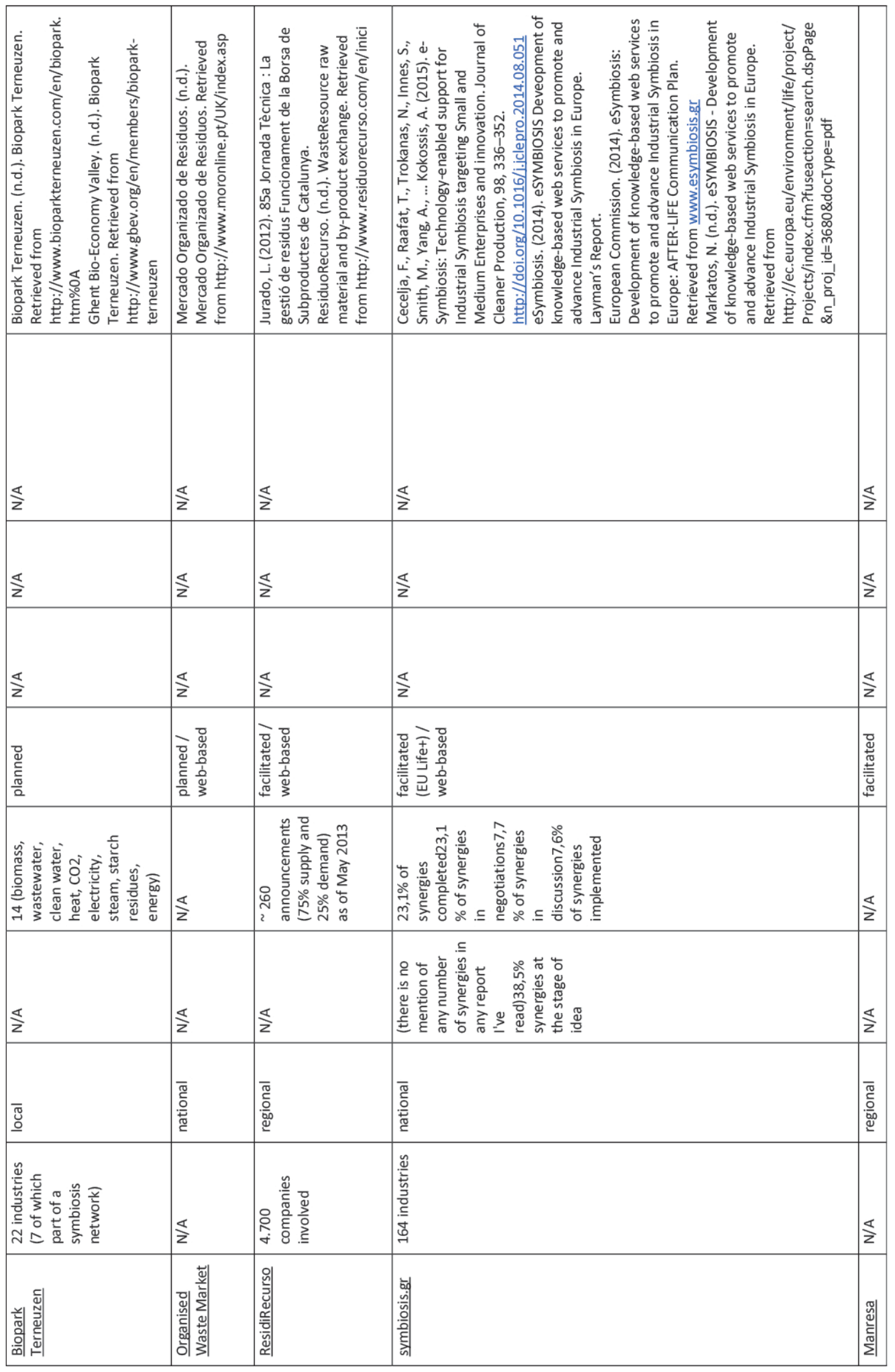




\begin{tabular}{|c|c|c|c|c|c|}
\hline 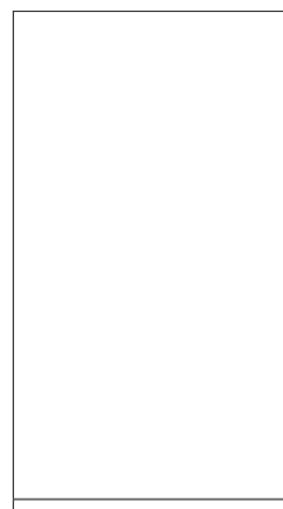 & 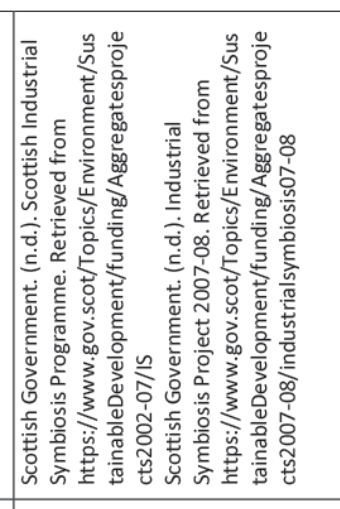 & & & 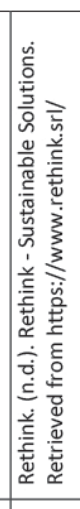 & 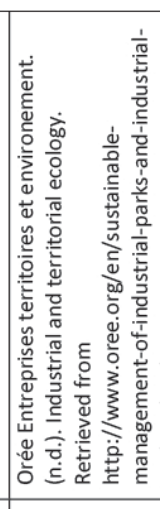 \\
\hline 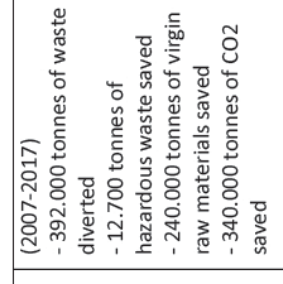 & 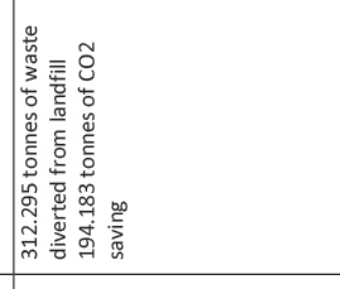 & $\frac{s}{2}$ & 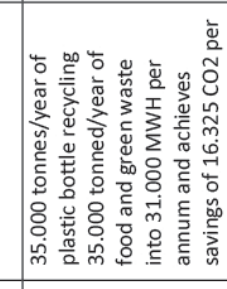 & $\frac{\pi}{2}$ & $\frac{\pi}{2}$ \\
\hline 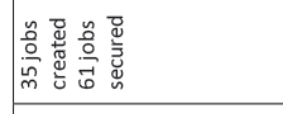 &  & $\frac{\pi}{2}$ & 耪器 & $\frac{s}{2}$ & $\frac{\pi}{z}$ \\
\hline 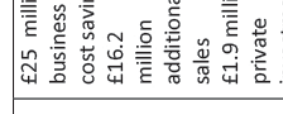 & $\begin{array}{l} \\
\end{array}$ & $\frac{x}{z}$ & $\frac{\pi}{z}$ & $\frac{s}{z}$ & $\frac{\pi}{2}$ \\
\hline 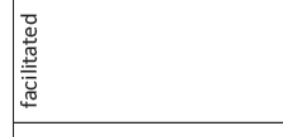 & 黑 & 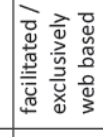 & 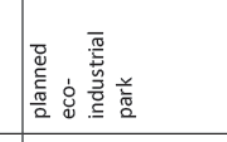 & 离离 & \\
\hline 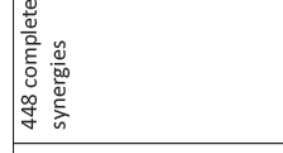 & 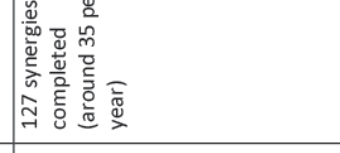 & $\frac{\pi}{2}$ & 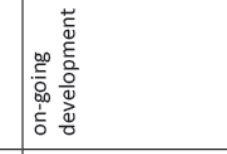 & 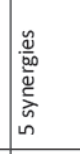 & 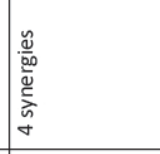 \\
\hline$\frac{s}{z}$ & $\frac{s}{z}$ & $\frac{s}{2}$ & $\frac{x}{z}$ & $\frac{s}{2}$ & $\frac{x}{2}$ \\
\hline 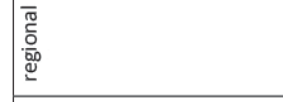 & $\mid$\begin{tabular}{|l}
$\mid \overline{\underline{z}}$ \\
\end{tabular} & 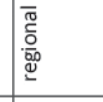 & $\frac{\bar{s}}{\underline{g}}$ & 薏 & $\frac{s}{2}$ \\
\hline 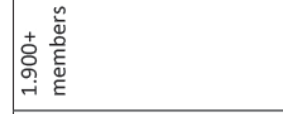 & $\frac{x}{z}$ & 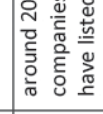 & 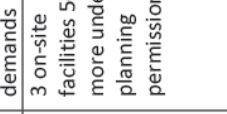 & 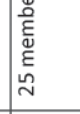 & \\
\hline$\frac{0}{2} \mid$ & $\frac{0.00}{0}$ & 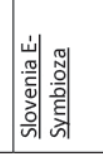 & : & 羊 & | \\
\hline
\end{tabular}




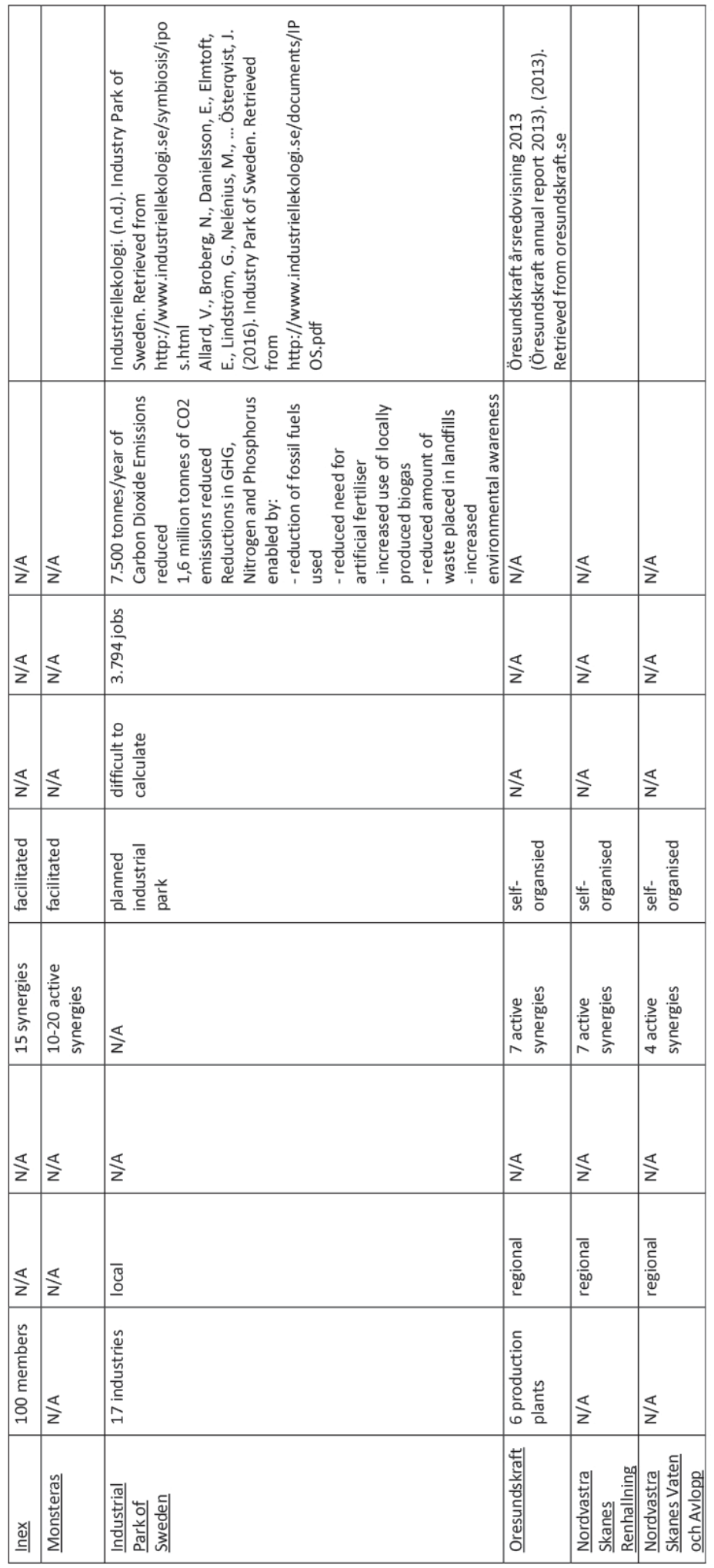




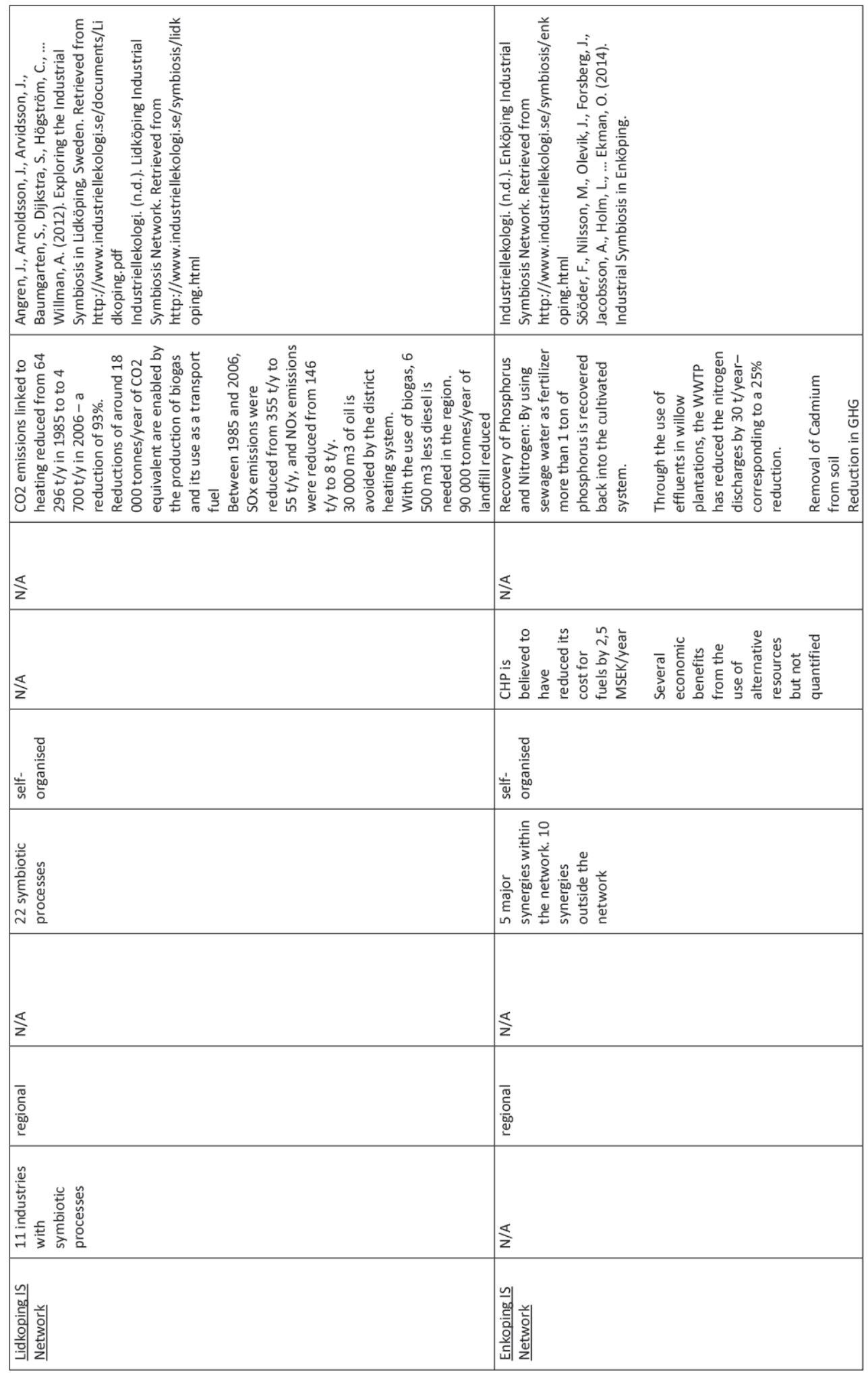




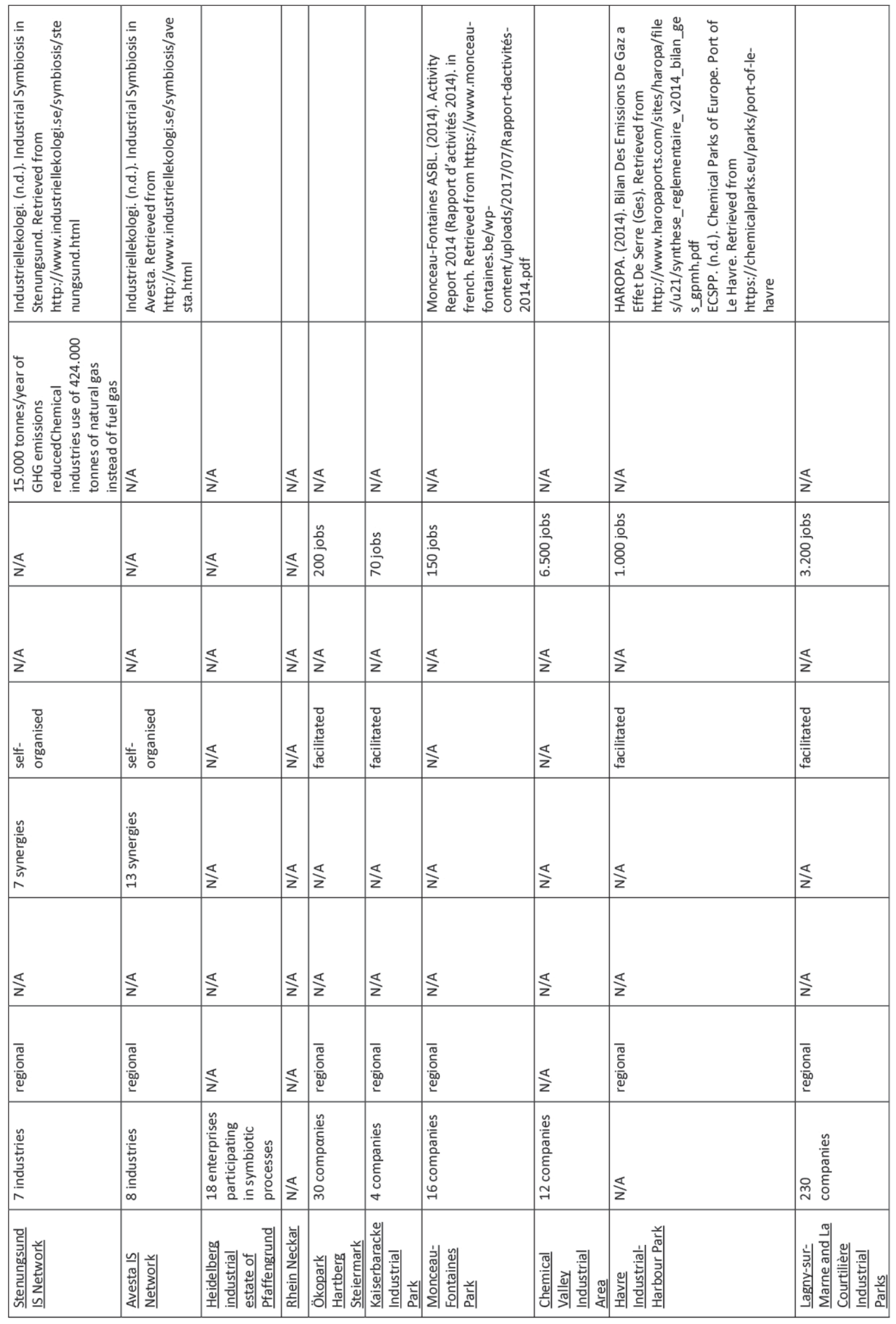




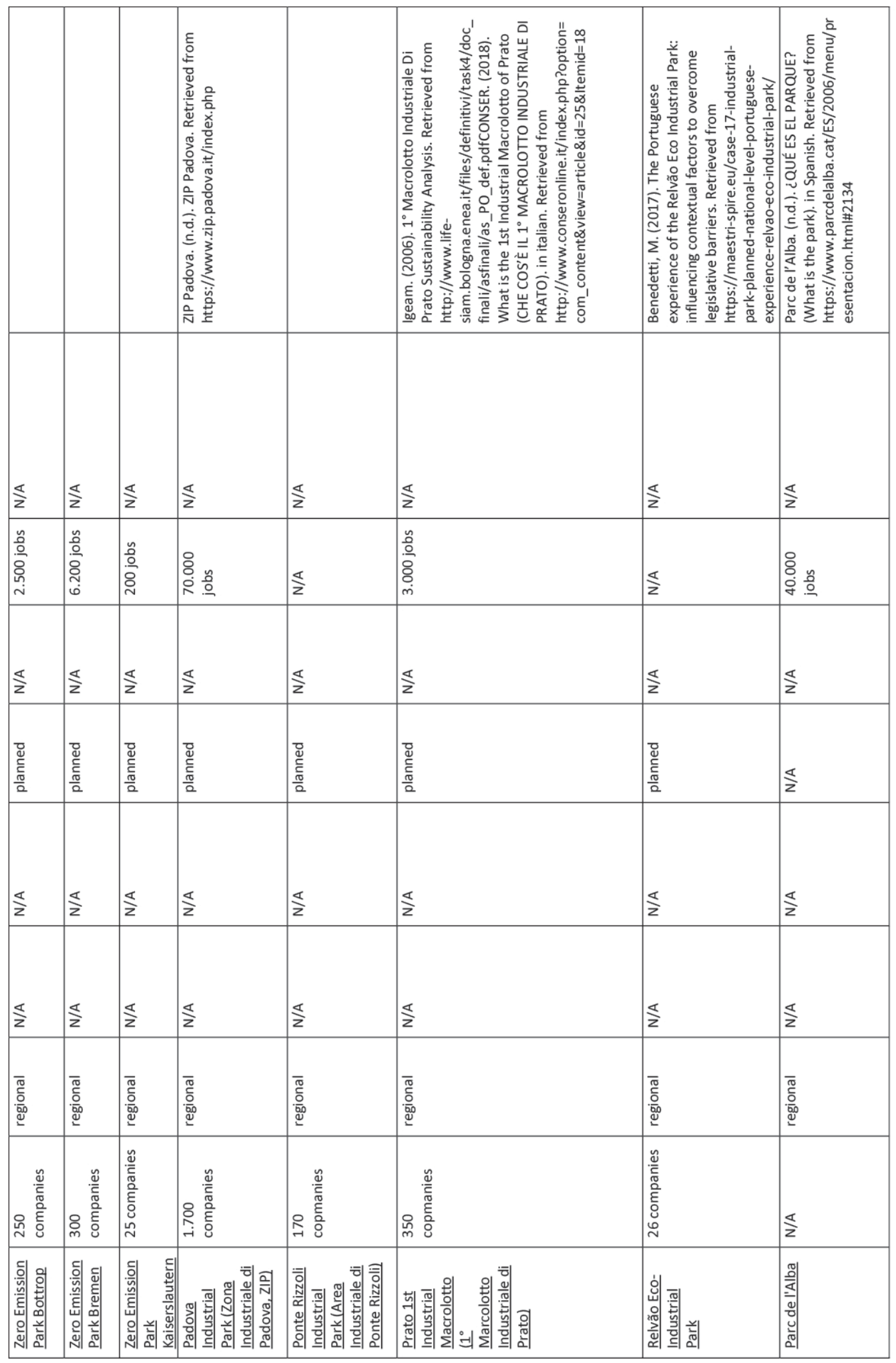




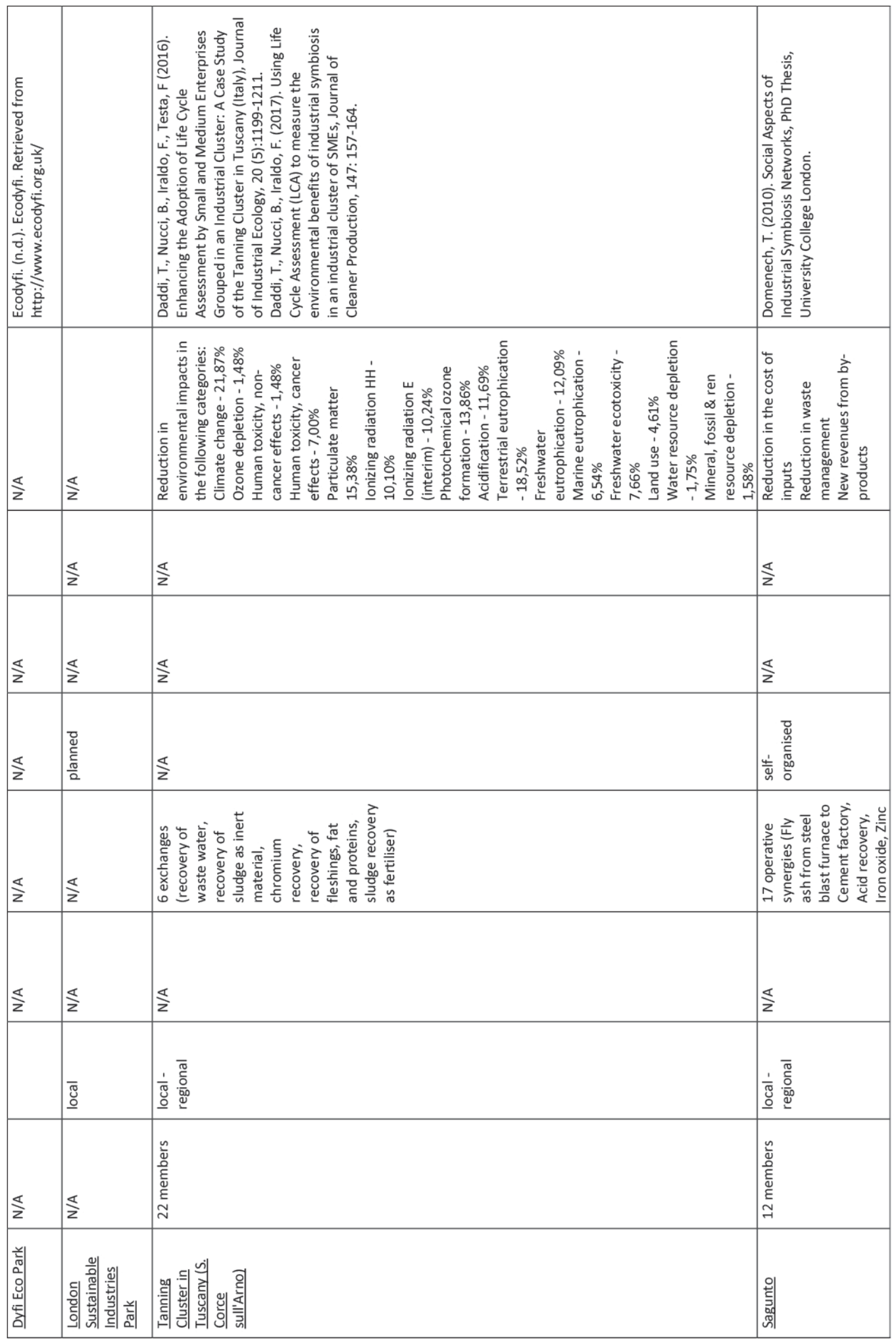




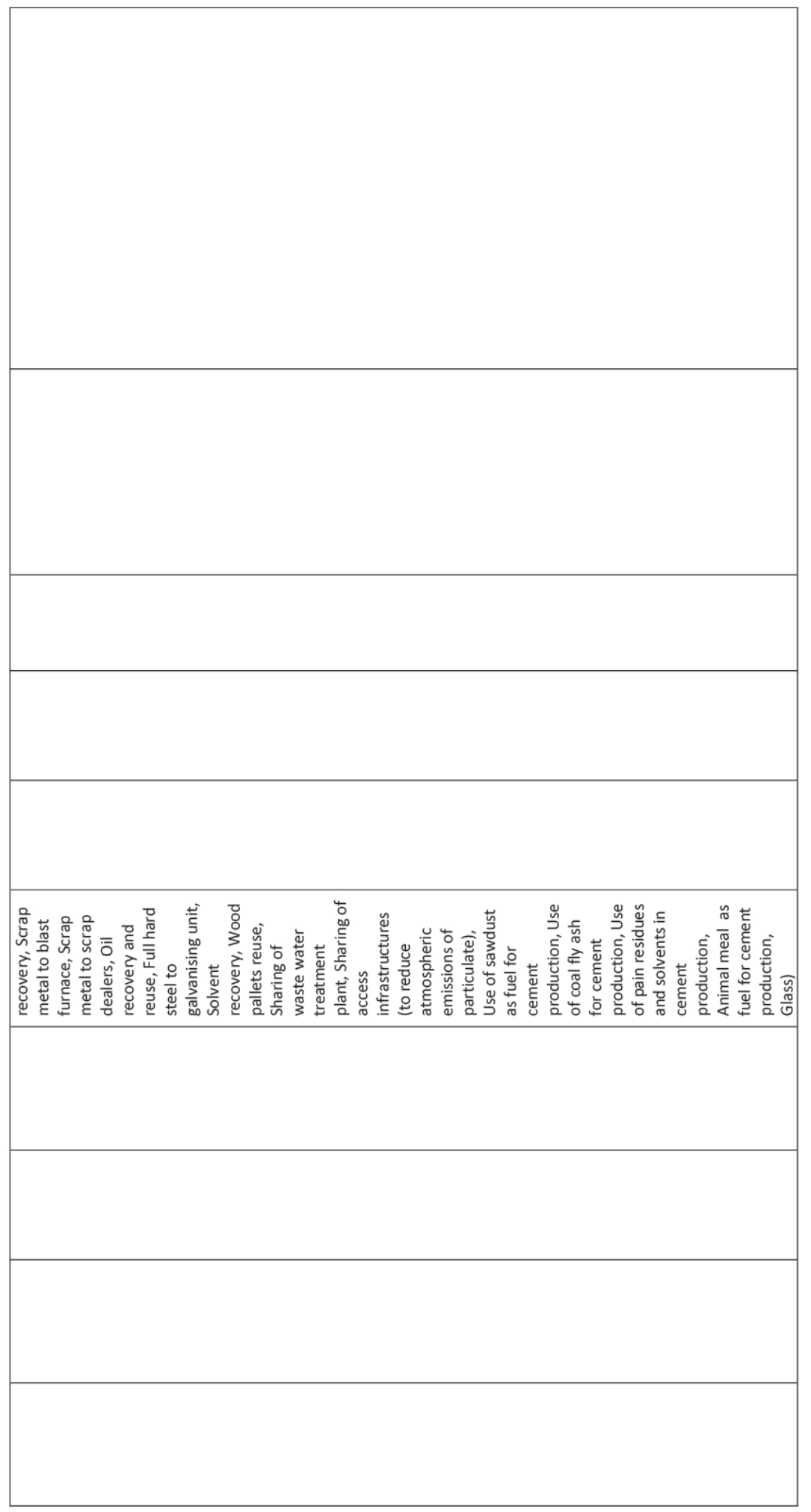

